\title{
Synchrotron-based XRD from rat bone of different age groups
}

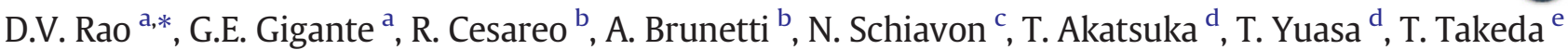 \\ a Science Based Applications to Engineering (SBAI), Physics Division, University of Rome “La Sapienza”, Via Scarpa 10, 00161 Roma, Italy \\ ${ }^{\mathrm{b}}$ Istituto di Matematica e Fisica, Università di Sassari, Via Vienna 2, 07100 Sassari, Italy \\ c Hercules Laboratory, University of Evora, Portugal \\ d Department of Bio-System Engineering, Faculty of Engineering, Yamagata University, Yonezawa-shi, Yamagata 992-8510, Japan \\ e Allied Health Science, Kitasato University, 1-15-1 Kitasato, Sagamihara, Kanagawa 228-8555, Japan
}

\section{A R T I C L E I N F O}

Article history:

Received 23 May 2016

Accepted 29 November 2016

Available online 3 December 2016

\section{Keywords:}

Synchrotron

X-rays

Diffraction

Rat bone

Different age groups

Phase

Crystal structure

SEM

\begin{abstract}
A B S T R A C T
Synchrotron-based XRD spectra from rat bone of different age groups (w, $56 \mathrm{w}$ and $78 \mathrm{w}$ ), lumber vertebra at early stages of bone formation, Calcium hydroxyapatite $(\mathrm{HAp})\left[\mathrm{Ca}_{10}\left(\mathrm{PO}_{4}\right)_{6}(\mathrm{OH})_{2}\right]$ bone fill with varying composition (60\% and 70\%) and bone cream (35-48\%), has been acquired with $15 \mathrm{keV}$ synchrotron X-rays. Experiments were performed at Desy, Hamburg, Germany, utilizing the Resonant and Diffraction beamline (P9), with $15 \mathrm{keV}$ $\mathrm{X}$-rays $\left(\lambda=0.82666 \mathrm{~A}^{0}\right)$. Diffraction data were quantitatively analyzed using the Rietveld refinement approach, which allowed us to characterize the structure of these samples in their early stages. Hydroxyapatite, received considerable attention in medical and materials sciences, since these materials are the hard tissues, such as bone and teeth. Higher bioactivity of these samples gained reasonable interest for biological application and for bone tissue repair in oral surgery and orthopedics. The results obtained from these samples, such as phase data, crystalline size of the phases, as well as the degree of crystallinity, confirm the apatite family crystallizing in a hexagonal system, space group $\mathrm{P}_{3} / \mathrm{m}$ with the lattice parameters of $a=9.4328 \AA$ and $c=6.8842 \AA$ (JCPDS card \#09-0432). Synchrotron-based XRD patterns are relatively sharp and well resolved and can be attributed to the hexagonal crystal form of hydroxyapatite. All the samples were examined with scanning electron microscope at an accelerating voltage of $15 \mathrm{kV}$. The presence of large globules of different sizes is observed, in small age groups of the rat bone ( $8 \mathrm{w}$ ) and lumber vertebra (LV), as distinguished from, large age groups (56 and 78w) in all samples with different magnification, reflects an amorphous phase without significant traces of crystalline phases. Scanning electron microscopy (SEM) was used to characterize the morphology and crystalline properties of Hap, for all the samples, from 2 to $100 \mu \mathrm{m}$ resolution.
\end{abstract}

C 2017 Elsevier B.V. All rights reserved.

\section{Motivation}

XRD spectra from bone (humans and animals) are studied extensively in a number ways to extract new and novel information about the $\mathrm{Ca} / \mathrm{P}$ ratio and over the years, calcium hydroxyapatite (HAp) $\left[\mathrm{Ca}_{10}\left(\mathrm{PO}_{4}\right)_{6}(\mathrm{OH})_{2}\right]$, has been used in biomedical engineering as a coating material in bone implants, to focus on interfacial reactions of a biological system and prosthesis for dental and bone repair. A key calcium phosphate ceramic mineral present in the human body. Hap is chemically and crystallographically equivalent to the mineral phase in bone. Hap has outstanding biological properties such as toxicity, lack of inflammatory response and absence of fibrous or immunological reactions. There has been a growing trend toward the development and use of biomaterials for repairing and restoration of damaged bone tissue and has been found to promote new bone formation when implanted in

\footnotetext{
* Corresponding author.

E-mail address: dvrao_9@yahoo.com (D.V. Rao).
}

a skeletal defect. The aim of the present study is to know, phase composition, purity, crystallinity, crystallite size, lattice parameters, of different age groups of rat bone, lumber vertebra and hydroxyapatite. Inview, of this more fundamental radiation interactions from these samples, will provide additional data, with the use of synchrotron sources, with higher flux [1-5].

The functional properties of Hap strongly depend on their morphology, stoichiometric ratio, crystallinity and crystal size distribution.Some samples that are of special interest in archeometry, such as bone, scatter $\mathrm{X}$-rays strongly and it is hard to obtain essential information conventional X-ray laboratory sources. This type ofdata can be obtained with detailed studies made with micro-focal optics at synchrotron sources.

The study of calcium phosphate-based ceramics has focused on mainly hydroxyapatite, $\left[\mathrm{Ca}_{10}\left(\mathrm{PO}_{4}\right)_{6}(\mathrm{OH})_{2}\right]$, due to its increased bioactive potential shown in several investigations. It exhibits a hexagonal crystal system with space group P63/m and contains a total of 44 atoms per unit cell. The unit cell contains two crystallographic sites of Ca ions: columnar and screw-axis Ca. Columnar Ca ions are aligned parallel to the 
c-axis at approximate unit-cell heights of 0 and $1 / 2$ and are linked by three shared $\mathrm{O}$ ions. Screw-axis $\mathrm{Ca}$ ions occur in two groups of three ions, with the $\mathrm{Ca}$ ions linked to a center $\mathrm{OH}$ group in the form of equilateral triangles. The triangles are orientated along the c-axis in the $a b$ plane. The six screw-axis Ca ions are bonded to PO4 groups, and these PO4 groups can be further linked to other $\mathrm{Ca}$ ions in the unit cell. The small crystal plates of $\mathrm{HAp}\left[\mathrm{Ca}_{10}\left(\mathrm{PO}_{4}\right)_{6}(\mathrm{OH})_{2}\right]$ are typically $50 \mathrm{~nm}$ in length, around $25 \mathrm{~nm}$ wide and on average $3 \mathrm{~nm}$ thick. Stoichiometric $\mathrm{HA}, \mathrm{Ca}_{10}\left(\mathrm{PO}_{4}\right)_{6}(\mathrm{OH}) 2$ in its commonest form, occurs as a hexagonally packed crystal [6-10].

The $\mathrm{Ca} / \mathrm{P}$ ratio (10:6) of some of the calcium phosphates used in medical applications, for example, hydroxyapatite, is 1.67. Due to the close similarity between nanometer scale forms of HAp and the mineral phase found in the natural bone matrix. Recent studies have focused on understanding the structure of HAp for its inclusion in a new generation of novel composites. Bone mineral is constituted of biological hydroxyapatite crystals. In developing bone, the mineral crystal matures and the $\mathrm{Ca} / \mathrm{P}$ ratio increases [11].

Synchrotron-based X-ray diffraction is a useful technique for determining crystal and molecular structures, to analyze the resulting diffraction data to determine the materials structure. To achieve this goal, several analysis techniques have been developed to resolve the diffraction data, since the publication of the original Rietveld method. With the advent of the Rietveld refinement technique, determining the crystalline structure from diffraction data has proven to be an indispensable tool for characterizing materials from X-ray diffraction data and as result, the technique is popular with crystallographers.

\section{Experimental}

Resonant and Diffraction beamline (P9) at Desy, Hamburg, Germany, is designed to operate the hard X-rays regime with energies ranging from 2.7 to $50 \mathrm{keV}$. Fig. 1 shows the experimental system used by the authors. X-rays with an energy of $15 \mathrm{keV}\left(\lambda=0.82666 \mathrm{~A}^{0}\right)$ were selected from the bending magnet source using a silicon double-crystal monochromator. The experimental hutch is dedicated to resonant Xray scattering and general diffraction experiments. The focus size is $150 \times 40 \mu \mathrm{m}^{2}$ and the energy resolution is $<1.4 \mathrm{eV}$ with $\mathrm{Si}$ (111) and for $\mathrm{Si}$ (311) it is $<0.3 \mathrm{eV}$. The experimental hutch is equipped with a highly flexible and precise Psi-diffractrometer with open Chi-circle. At the sample position, a simple goniometer mount, Displex cryostats or small sample environments, like ovens, can be mounted on the motorized xyz-translation stage. The detector arms consist of two translations separated by $25^{\circ}$. X-rays are detected using the area detector and

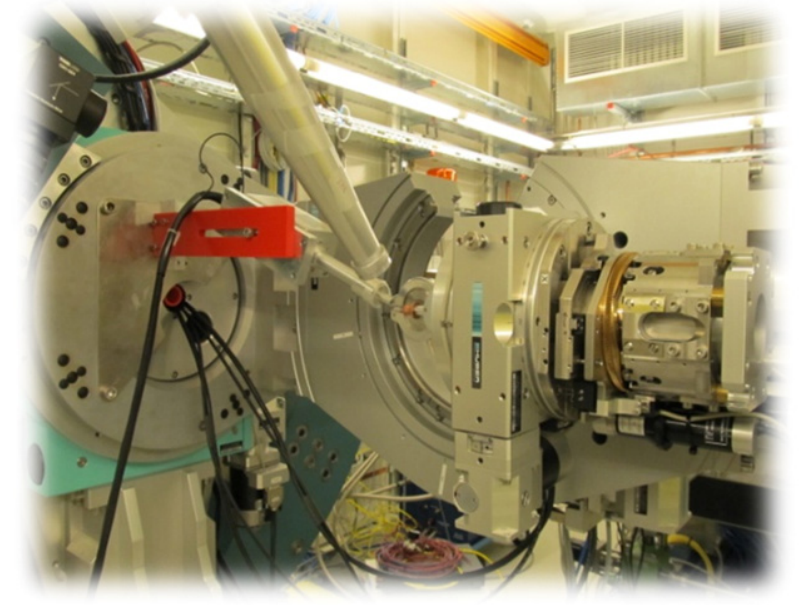

Fig. 1. Experimental system used by the author's at Desy: P9, diffraction beamline.
Table 1

Hydroxyapatite phantom dimensions.

\begin{tabular}{|c|c|c|c|}
\hline Name & Sample & Dimensions & Hydroxyapatite (\%) \\
\hline $\begin{array}{l}\text { BONEFIL } 60 \\
60\end{array}$ & Phantom pellet & & $10 \mathrm{~mm} \times 10 \mathrm{~mm}$ \\
\hline $\begin{array}{l}\text { BONEFIL } 70 \\
70\end{array}$ & Phantom pellet & & $10 \mathrm{~mm} \times 10 \mathrm{~mm}$ \\
\hline $\begin{array}{l}\text { BONECERAM } \\
35-48\end{array}$ & Phantom pellet & & $8 \mathrm{~mm} \times 10 \mathrm{~mm}$ \\
\hline
\end{tabular}

mythen detector at an angle designated by the label $2 \theta$, referenced to the direct incoming beam. The magnitude of the momentum transfer $q$ is a function of $2 \theta$, the scattering angle: $q=(4 \pi / \lambda) \operatorname{Sin}(2 \theta / 2)$. The diffraction peaks presented in this work, varies upto 65 degrees $\left(0<2 \theta<65^{\circ}\right)$, with a step of $0.02^{\circ}$ at $5 \mathrm{~s} / \mathrm{step}$, with minimum sample tilts in the transverse direction. The data was converted to two-dimensional $2 \theta$ intensity data for the analysis of the samples.

\section{Scanning electron microscopy}

Researchers studied, the bone and associated morphology using SEM to magnify the features which will assist with identifying and classifying different spices. A high-resolution scanning electron microscope (HR-SEM, ULTRA Plus, Zeiss, Germany) was used for characterization of the crystal shape and morphology. To investigate the present samples, the SEM was operated at an accelerating voltage of $20 \mathrm{kV}$ and current of $10 \mathrm{~mA}$ for imaging and the associated morphology. Samples were prepared for scanning electron microscopy (SEM) by mounting the dried samples on an aluminum stub covered in double-sided copper tape, then sputter coated with either $\mathrm{Au} / \mathrm{Pd}$ or amorphous carbon.

\section{Samples}

A number of rat's bone and lumbar vertebra samples $(10 \times 10 \mathrm{~mm}$; $10 \times 8 \mathrm{~mm})$ of different ages $(8,56$ and 78 weeks) were prepared from Wistar rats, and these samples are used for XRD. All procedures were approved by the Animal Research Committee of the University.

\section{Rietveld analysis}

The raw data from the XRD scans were inputted into the FullProf program [12]. Rietveld analysis software program developed for crystallographic refinement. The HAp crystal model was built using information from the International Crystal Structure Database (ICSD). The dimensions of the hydroxyapatite are mentioned in Table1. The details

Table 2

Hydroxyapatite crystal structure parameters, refined by Rietveld analysis.

\begin{tabular}{|c|c|c|c|c|c|c|c|}
\hline \multicolumn{8}{|l|}{ Phase data } \\
\hline \multicolumn{5}{|l|}{$\begin{array}{l}\text { Space-group } \\
\text { Cell }\end{array}$} & \multicolumn{3}{|c|}{$\begin{array}{l}\text { P63/m (176)-hexagonal } \\
a=9.4239 \AA, c=6.8841 \AA \\
c / a=0.7305 \\
Z=1, \gamma=120^{0} \\
V=529.47 \AA^{3}, \alpha=\beta=90^{\circ}\end{array}$} \\
\hline Atom $0 x$. & Wyck. & Site & S.O.F. & $\mathrm{x} / \mathrm{a}$ & $\mathrm{y} / \mathrm{b}$ & $\mathrm{z} / \mathrm{c}$ & $\mathrm{U}\left[\AA^{2}\right]$ \\
\hline Ca1 & $4 f$ & $3 \ldots$ & & $1 / 3$ & $2 / 3$ & 0.00130 & 0.0037 \\
\hline $\mathrm{Ca} 2$ & $12 \mathrm{i}$ & 1 & 0.33333 & 0.24620 & 0.99260 & 0.22220 & 0.0037 \\
\hline P1 & $12 \mathrm{i}$ & 1 & 0.33333 & 0.39880 & 0.36910 & 0.22220 & 0.0048 \\
\hline 01 & $12 \mathrm{i}$ & 1 & 0.33333 & 0.32600 & 0.48300 & 0.22220 & 0.0015 \\
\hline $\mathrm{O} 2$ & $12 \mathrm{i}$ & 1 & 0.33333 & 0.58750 & 0.46530 & 0.22220 & 0.0015 \\
\hline $\mathrm{O} 3$ & $12 \mathrm{i}$ & 1 & 0.33333 & 0.34070 & 0.25590 & 0.07040 & 0.0015 \\
\hline 04 & $4 \mathrm{e}$ & $3 \ldots$ & 0.5 & 0 & 0 & 0.20300 & 0.0015 \\
\hline $\mathrm{H} 4$ & $4 e$ & $3 \ldots$ & 0.5 & 0 & 0 & 0.07300 & 0.0157 \\
\hline
\end{tabular}




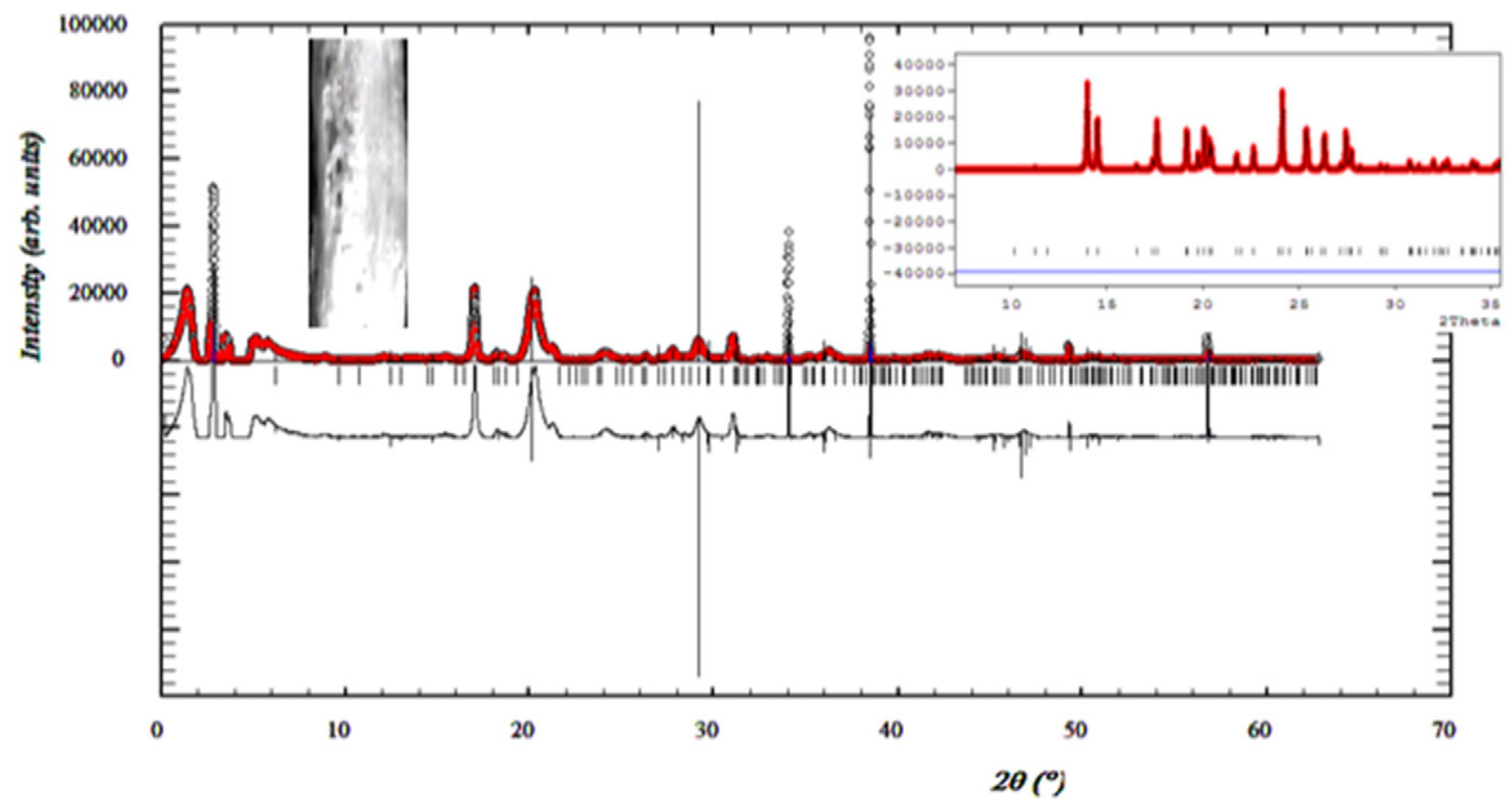

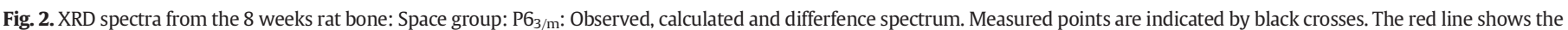

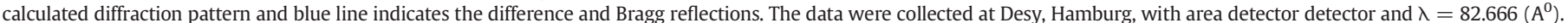

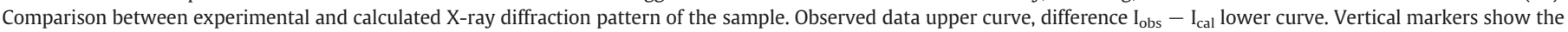
calculated position for Bragg reflections. The inset shows the Rietveld refinement, and the physical dimension of the sample used.

of the crystallographic model are listed in Table 2. Peak shapes were modeled using the pseudo-Voigt function, and two asymmetry parameters were refined. In each case, four background parameters, a scale factor, five peak-shape parameters, $2 \theta$ offset (zero point correction), sample displacement, cell parameters, and atomic positions were all refined. The peak at $33^{\circ}$ is too broad to resolve the separate (211), (112) and $\left(\begin{array}{lll}3 & 0 & 0\end{array}\right)$ peaks, but an overall peak shift is seen relative to HAp, as is also found for bone. The X-ray diffraction studies show initially broad

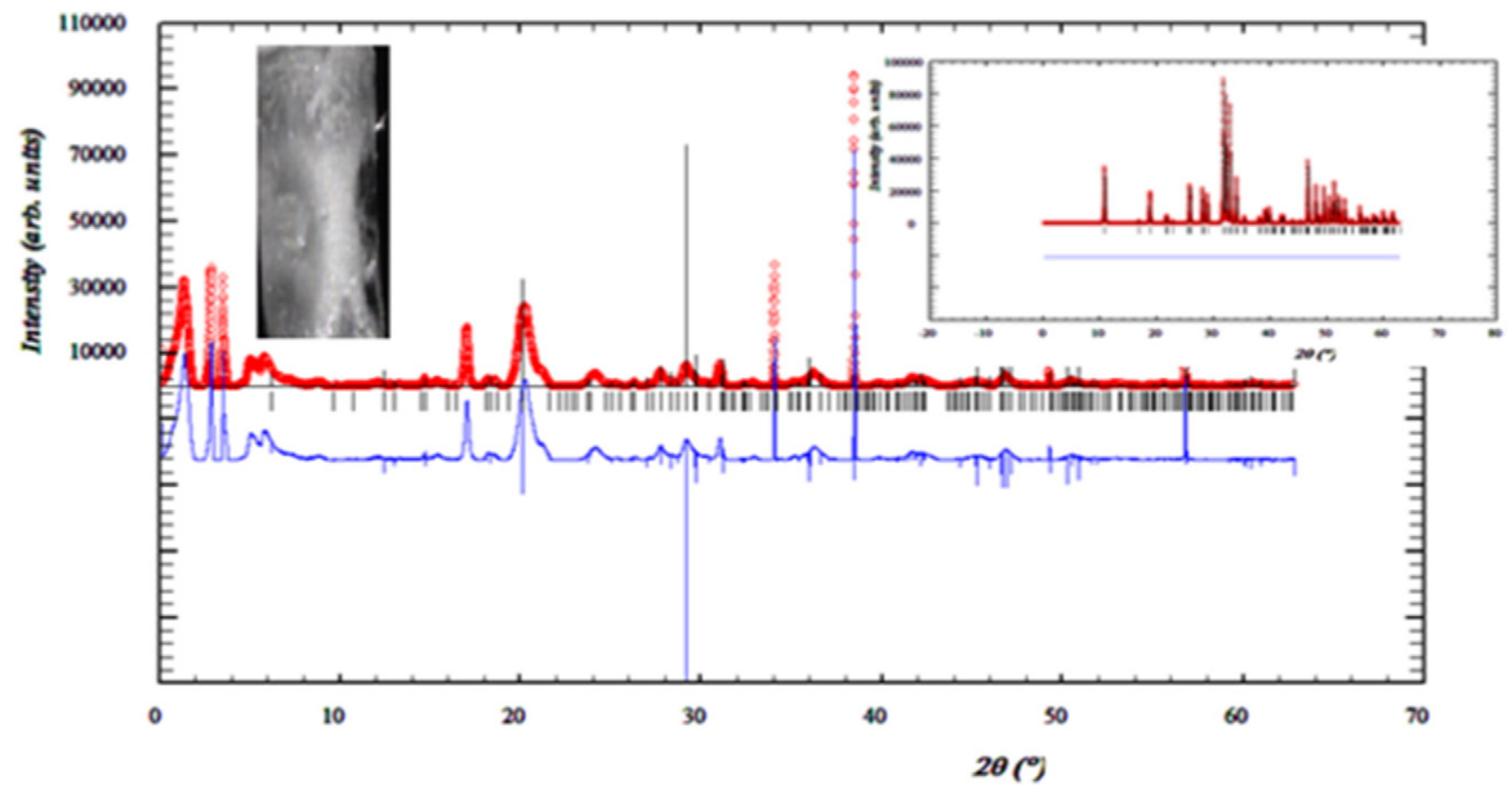

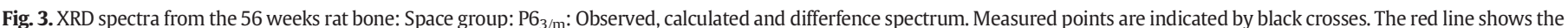

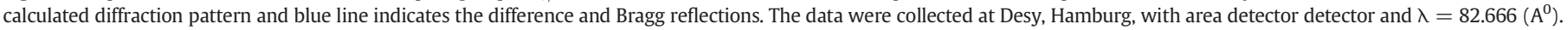

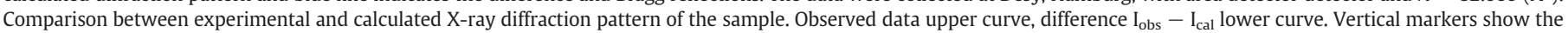
calculated position for Bragg reflections. The inset shows the Rietveld refinement, and the physical dimension of the sample used. 


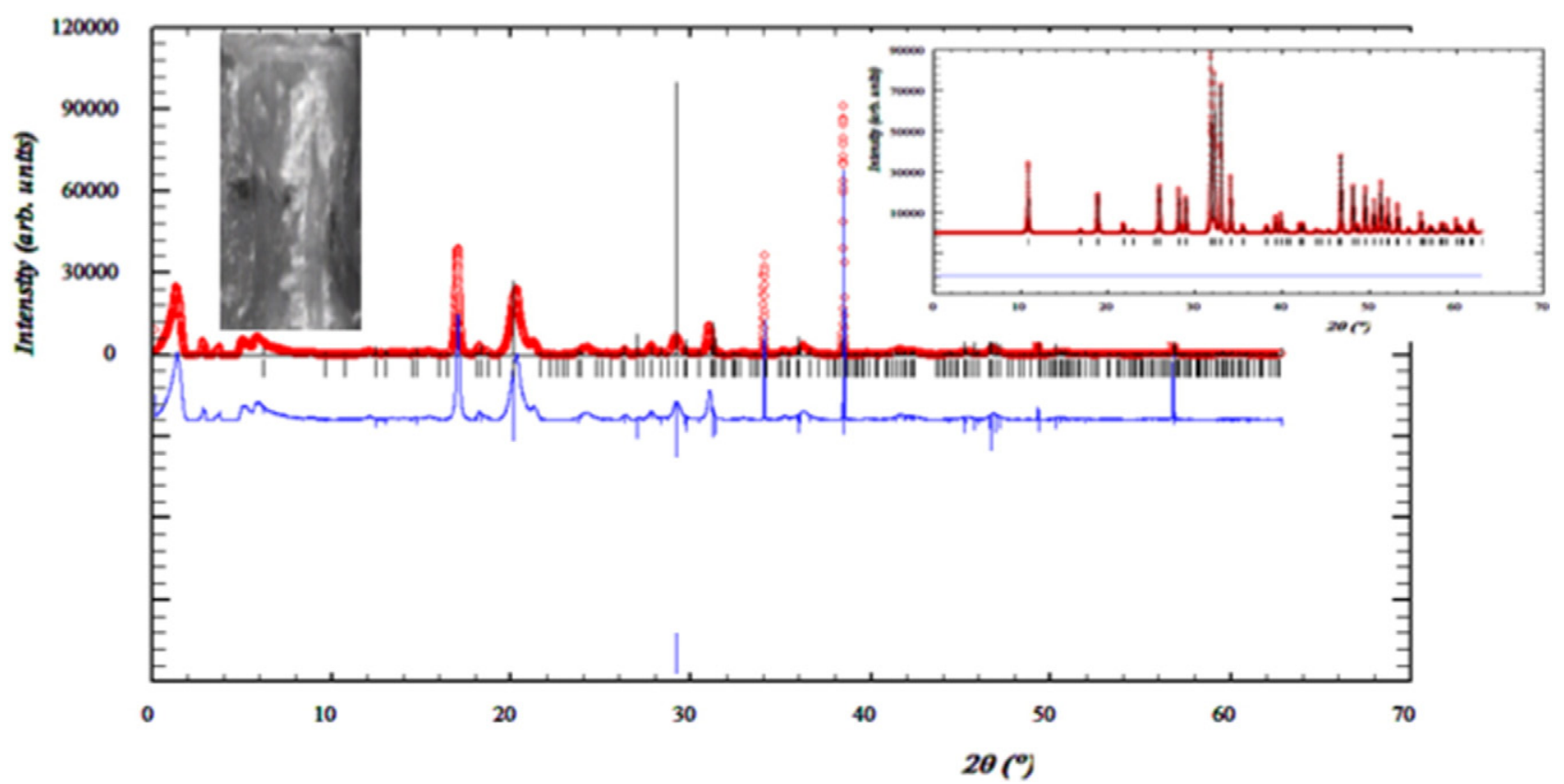

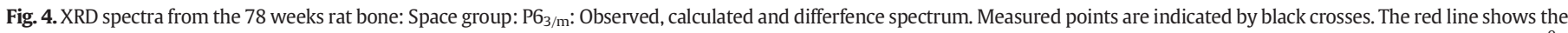

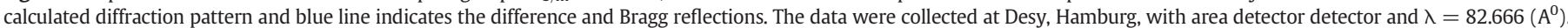

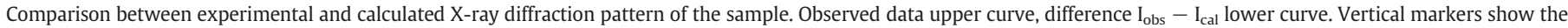
calculated position for Bragg reflections. The inset shows the Rietveld refinement, and the physical dimension of the sample used.

peaks that sharpen with time. The data alone, however, are insufficient to conclude that the mineral is amorphous, because the initial broad peaks could arise from a collection of ordered crystals of nanometer dimensions, and subsequent growth of the small ordered crystals to larger ordered crystals could account for the narrowing of the XRD peaks. The peak narrowing in this XRD series suggest that crystals are indeed forming, which we interpret to mean they are growing from an already present amorphous phase.

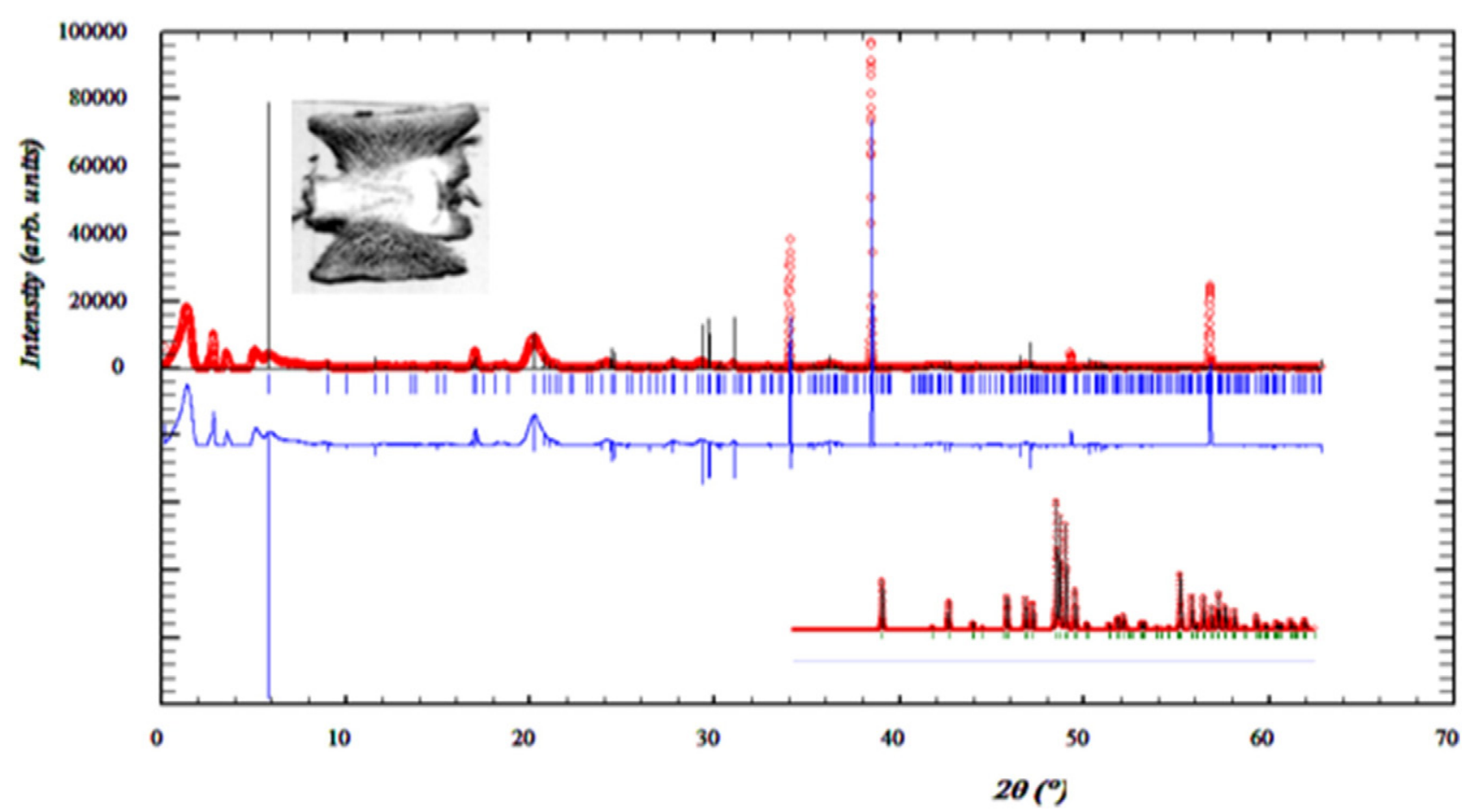

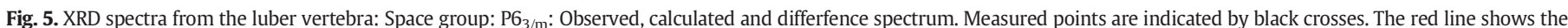

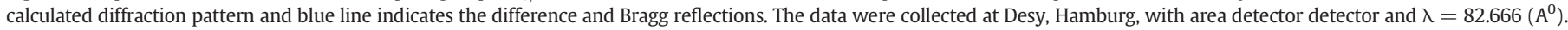

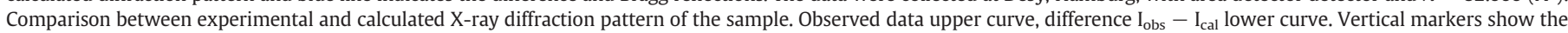
calculated position for Bragg reflections. The inset shows the Rietveld refinement, and the physical dimension of the sample used. 


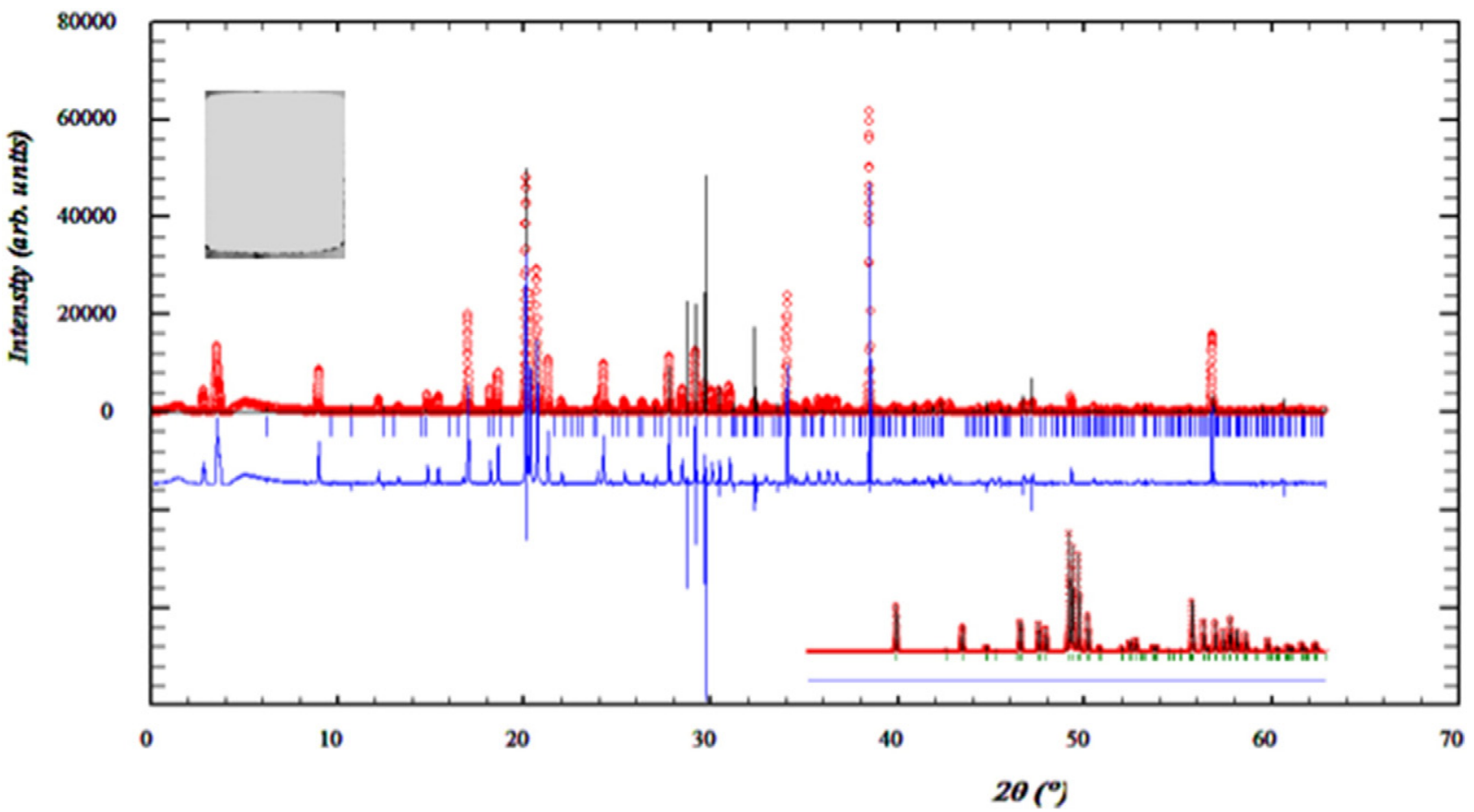

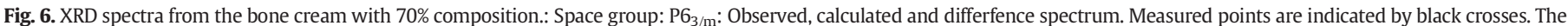

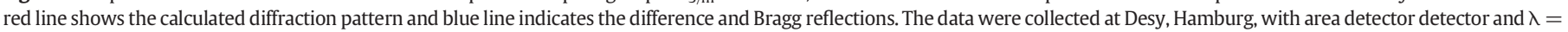

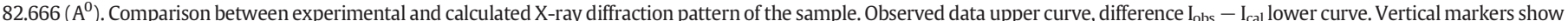
the calculated position for Bragg reflections. The inset shows the Rietveld refinement, and the physical dimension of the sample used.

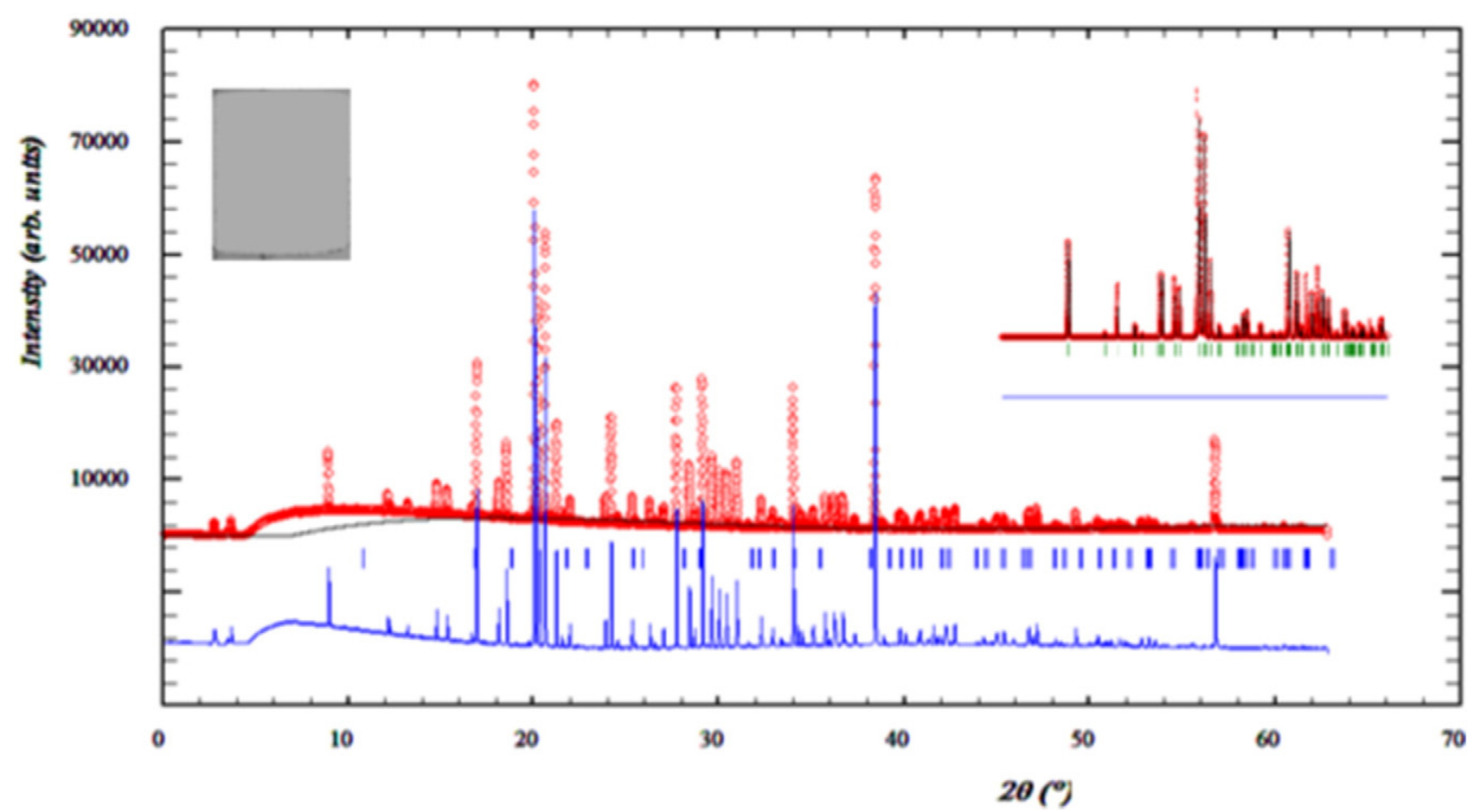

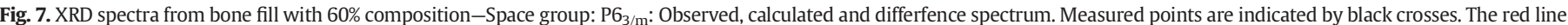

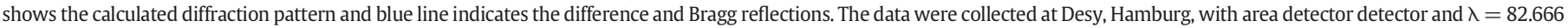

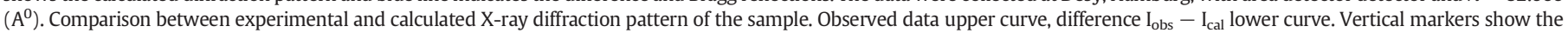
calculated position for Bragg reflections. The inset shows the Rietveld refinement, and the physical dimension of the sample used. 


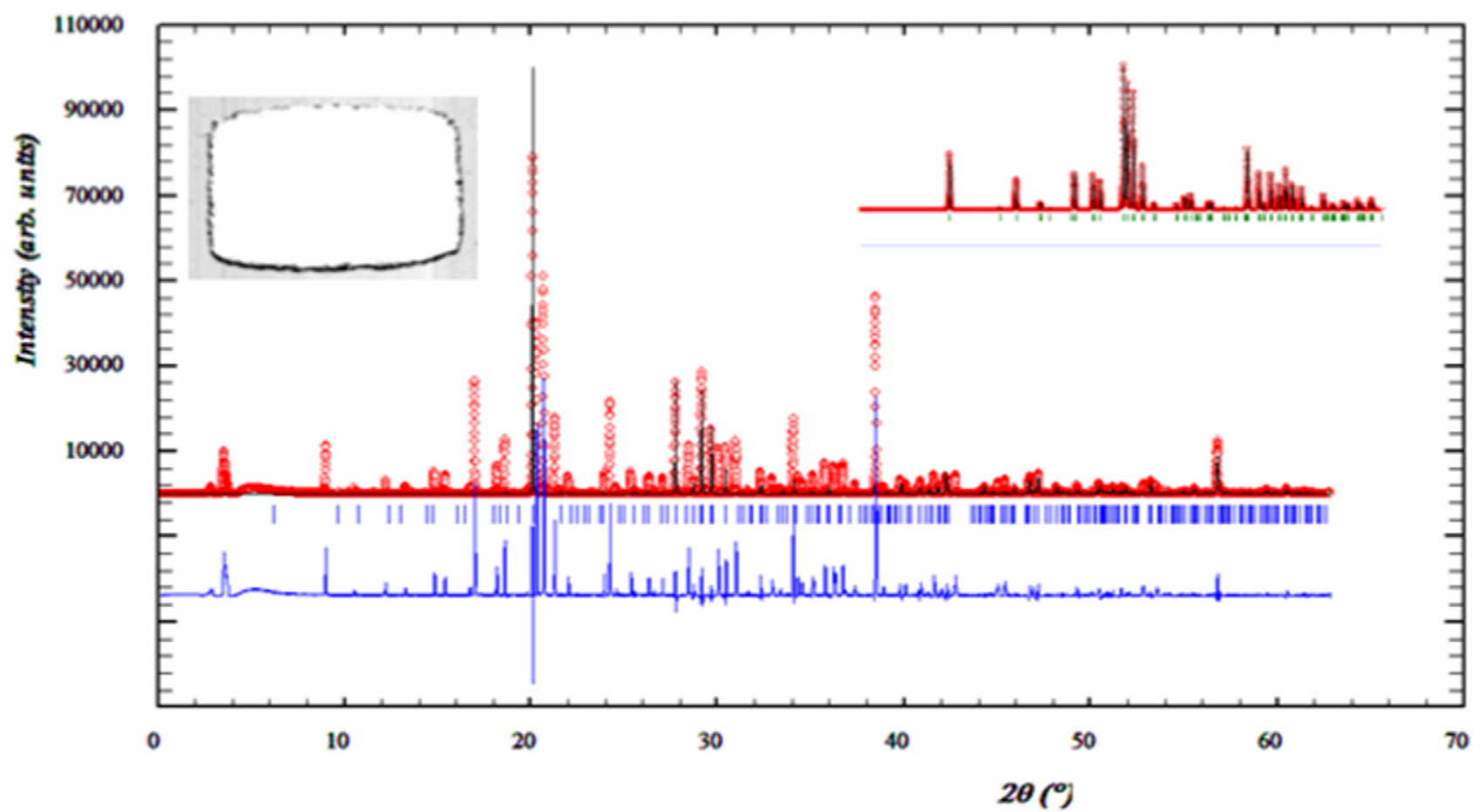

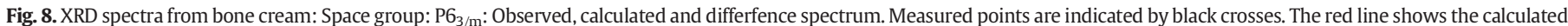

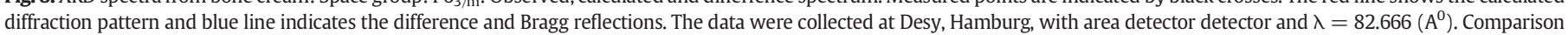

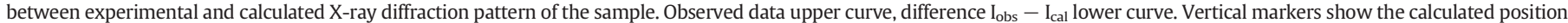
for Bragg reflections. The inset shows the Rietveld refinement, and the physical dimension of the sample used.

\section{Results}

Diffraction patterns were recorded using point and area detectors, mounted perpendicular to the incident beam. The use of point and

Table 3

$2 \theta$ and $h, k, l$ positions of the samples at $0.82666\left(A^{0}\right)$.

$$
\begin{aligned}
& 10.8310\left(\begin{array}{lll}
0 & 1 & 0
\end{array}\right) \\
& 10.8580\left(\begin{array}{lll}
0 & 1 & 0
\end{array}\right) \\
& 16.8350\left(\begin{array}{lll}
0 & 1 & 1
\end{array}\right) \\
& 16.8770\left(\begin{array}{lll}
0 & 1 & 1
\end{array}\right) \\
& 18.8170\left(\begin{array}{lll}
1 & 1 & 0
\end{array}\right) \\
& 18.8640\left(\begin{array}{lll}
1 & 1 & 0
\end{array}\right) \\
& 21.7610\left(\begin{array}{lll}
0 & 2 & 0
\end{array}\right) \\
& 21.8160\left(\begin{array}{lll}
0 & 2 & 0
\end{array}\right) \\
& 22.8520\left(\begin{array}{lll}
1 & 1 & 1
\end{array}\right) \\
& 22.9090\left(\begin{array}{lll}
1 & 1 & 1
\end{array}\right) \\
& 25.3520\left(\begin{array}{lll}
0 & 2 & 1
\end{array}\right) \\
& 25.4160\left(\begin{array}{lll}
0 & 2 & 1
\end{array}\right) \\
& 25.8630\left(\begin{array}{lll}
0 & 0 & 2
\end{array}\right) \\
& 25.9280\left(\begin{array}{lll}
0 & 0 & 2
\end{array}\right) \\
& 28.1120\left(\begin{array}{lll}
0 & 1 & 2
\end{array}\right) \\
& 28.1840\left(\begin{array}{lll}
0 & 1 & 2
\end{array}\right) \\
& 28.9210\left(\begin{array}{lll}
1 & 2 & 0
\end{array}\right) \\
& 28.9210\left(\begin{array}{lll}
2 & 1 & 0
\end{array}\right) \\
& 28.9940\left(\begin{array}{lll}
1 & 2 & 0
\end{array}\right) \\
& 28.9940\left(\begin{array}{lll}
2 & 1 & 0
\end{array}\right) \\
& 31.7610\left(\begin{array}{lll}
1 & 2 & 1
\end{array}\right) \\
& 31.7610\left(\begin{array}{lll}
2 & 1 & 1
\end{array}\right) \\
& 31.8420\left(\begin{array}{lll}
1 & 2 & 1
\end{array}\right) \\
& 31.8420\left(\begin{array}{lll}
2 & 1 & 1
\end{array}\right) \\
& 32.1790\left(\begin{array}{lll}
1 & 1 & 2
\end{array}\right) \\
& 32.2610\left(\begin{array}{lll}
1 & 1 & 2
\end{array}\right) \\
& 32.8960\left(\begin{array}{lll}
0 & 3 & 0
\end{array}\right) \\
& 32.9800\left(\begin{array}{lll}
0 & 3 & 0
\end{array}\right) \\
& 34.0470\left(\begin{array}{lll}
0 & 2 & 2
\end{array}\right) \\
& 34.1340\left(\begin{array}{lll}
0 & 2 & 2
\end{array}\right) \\
& 35.4500\left(\begin{array}{lll}
0 & 3 & 1
\end{array}\right) \\
& 35.5410\left(\begin{array}{lll}
0 & 3 & 1
\end{array}\right)
\end{aligned}
$$

area detectors allows diffraction patterns to be collected with high counting statistics and greatly reduced acquisition times. These characteristics were well suited to this experiment, because, we were dealing with a relatively large number of weakly scattering samples. XRD spectra were analyzed using the Rietveld structural refinement approach as implemented in the FullProf software.

Figs. 2 to 5 shows the observed, calculated and difference spectra from 8, 56 and 78 weeks rat bone and lumber vertebra. Figs. 6 to 8 shows the observed, calculated and difference spectra of the bone fill with varying composition (60 and 70\%) and bone cream (35-48\%). Measured points are indicated by black crosses. The red line shows the calculated diffraction pattern and blue line indicates the difference and Bragg reflections. The inset shows the Rietveld refinement, with the physical dimension of the sample used for the measurements. Compared the experimental and calculated X-ray diffraction pattern for each sample, with observed data as upper curve, difference $\mathrm{I}_{\text {obs }}-\mathrm{I}_{\text {cal }}$ as lower curve. Vertical markers show the calculated position for Bragg reflections. The analysis of the samples, reveals the presence of crystalline nano-metre sized HAp phases, which were found to be consistent with the phases listed in the ICDD database. The main $(h k l)$ indices for nano-metre sized HAp: (002), (211), (300), (202), (130), (002), (222) and (213) being indicated in Figs.2 to 8. Table3 shows the reflections from the samples. Table 4 shows the group of atoms. Table 5 shows the distances/angles and atom wise symmetry operation for the sample

Table 4

Atom groups.

\begin{tabular}{lllll}
\hline No & Symbol & $\begin{array}{l}\text { Effective radius } \\
\left(\mathrm{A}^{0}\right)\end{array}$ & $\begin{array}{l}\text { Drawing radius } \\
\left(\mathrm{A}^{0}\right)\end{array}$ & $\begin{array}{l}\text { Van-der-Waals radius } \\
\left(\mathrm{A}^{0}\right)\end{array}$ \\
\hline 1 & $\mathrm{Ca}$ & 1.8 & 0.570 & 2.600 \\
2 & $\mathrm{P}$ & 1.0 & 0.285 & 1.800 \\
3 & $\mathrm{O}$ & 0.6 & 0.255 & 1.520 \\
4 & $\mathrm{H}$ & 0.25 & 0.135 & 1.200 \\
\hline
\end{tabular}


Table 5

Distances/angles and atom-wise symmetry operations for the sample, calcium hydroxyapatite.

\begin{tabular}{|c|c|c|c|c|c|c|c|}
\hline Atom 1 & Atom 2 & Symmetry op. 2 & d $1,2[\AA]$ & Atom 3 & Symmetry op. 3 & d 1,3 [Å] & Angle $2,1,3\left[^{\circ}\right]$ \\
\hline Ca1 & 01 & $\mathrm{x}, \mathrm{y}, \mathrm{z}$ & 22.777 & 01 & $-\mathrm{x}+\mathrm{y}, 1-\mathrm{x}, \mathrm{z}$ & 22.780 & 80.380 \\
\hline Ca1 & 01 & $-\mathrm{x}+\mathrm{y}, 1-\mathrm{x}, \mathrm{z}$ & 22.780 & 01 & $1-\mathrm{y}, 1+\mathrm{x}-\mathrm{y}, \mathrm{z}$ & 22.784 & 80.365 \\
\hline Ca1 & 01 & $1-y, 1+x-y, z$ & 22.784 & $\mathrm{O} 2$ & $1-\mathrm{x}, 1-\mathrm{y},-\mathrm{z}$ & 23.223 & 120.109 \\
\hline Ca1 & $\mathrm{O} 2$ & $1-\mathrm{x}, 1-\mathrm{y},-\mathrm{z}$ & 23.223 & $\mathrm{O} 2$ & $\mathrm{x}-\mathrm{y}, \mathrm{x},-\mathrm{z}$ & 23.224 & 80.969 \\
\hline Ca1 & $\mathrm{O} 2$ & $\mathrm{x}-\mathrm{y}, \mathrm{x},-\mathrm{z}$ & 23.224 & $\mathrm{O} 2$ & $y, 1-x+y,-z$ & 23.229 & 80.955 \\
\hline $\mathrm{Ca} 2$ & $\mathrm{Ca} 2$ & $\mathrm{x}, \mathrm{y}, 0.5-\mathrm{z}$ & 0.3855 & $\mathrm{O} 3$ & $y, 1-x+y,-z$ & 21.584 & 158.840 \\
\hline $\mathrm{Ca} 2$ & $\mathrm{O} 3$ & $y, 1-x+y,-z$ & 21.584 & $\mathrm{O} 2$ & $1-y, 1+x-y, z$ & 23.586 & 86.696 \\
\hline $\mathrm{Ca} 2$ & $\mathrm{O} 4$ & $\mathrm{x}, 1+\mathrm{y}, \mathrm{z}$ & 23.594 & $\mathrm{O} 2$ & $\begin{array}{l}1-y, 1+x-y \\
0.5-z\end{array}$ & 23.899 & 151.411 \\
\hline $\mathrm{Ca} 2$ & $\mathrm{O} 2$ & $\begin{array}{l}1-y, 1+x-y \\
0.5-z\end{array}$ & 23.899 & 04 & $-x+y, 1-x, 0.5-z$ & 24.117 & 144.662 \\
\hline $\mathrm{Ca} 2$ & 04 & $-x+y, 1-x, 0.5-z$ & 24.117 & 03 & $\mathrm{x}, 1+\mathrm{y}, \mathrm{z}$ & 24.144 & 85.909 \\
\hline P1 & P1 & $\mathrm{x}, \mathrm{y}, 0.5-\mathrm{z}$ & 0.3855 & 03 & $\mathrm{x}, \mathrm{y}, \mathrm{z}$ & 13.939 & 138.480 \\
\hline P1 & $\mathrm{O} 3$ & $\mathrm{x}, \mathrm{y}, \mathrm{z}$ & 13.939 & 01 & $\mathrm{x}, \mathrm{y}, \mathrm{z}$ & 15.360 & 113.145 \\
\hline P1 & 01 & $\mathrm{x}, \mathrm{y}, \mathrm{z}$ & 15.360 & $\mathrm{O} 2$ & $\mathrm{x}, \mathrm{y}, \mathrm{z}$ & 15.401 & 112.108 \\
\hline P1 & $\mathrm{O} 2$ & $\mathrm{x}, \mathrm{y}, \mathrm{z}$ & 15.401 & $\mathrm{O} 3$ & $\mathrm{x}, \mathrm{y}, 0.5-\mathrm{z}$ & 17.018 & 106.492 \\
\hline P1 & 01 & $\mathrm{x}, \mathrm{y}, 0.5-\mathrm{z}$ & 15.836 & $\mathrm{O} 2$ & $\mathrm{x}, \mathrm{y}, 0.5-\mathrm{z}$ & 15.877 & 107.157 \\
\hline P1 & $\mathrm{O} 2$ & $\mathrm{x}, \mathrm{y}, 0.5-\mathrm{z}$ & 15.877 & $\mathrm{O} 3$ & $\mathrm{x}, \mathrm{y}, 0.5-\mathrm{z}$ & 17.018 & 94.099 \\
\hline 01 & 01 & $\mathrm{x}, \mathrm{y}, 0.5-\mathrm{z}$ & 0.3855 & P1 & $\mathrm{x}, \mathrm{y}, \mathrm{z}$ & 15.360 & 90.000 \\
\hline 01 & P1 & $\mathrm{x}, \mathrm{y}, \mathrm{z}$ & 15.360 & 03 & $\mathrm{x}, \mathrm{y}, \mathrm{z}$ & 24.465 & 31.594 \\
\hline 01 & P1 & $\mathrm{x}, \mathrm{y}, 0.5-\mathrm{z}$ & 15.836 & Ca1 & $\mathrm{x}, \mathrm{y}, \mathrm{z}$ & 22.777 & 144.936 \\
\hline 01 & P1 & $\mathrm{x}, \mathrm{y}, 0.5-\mathrm{z}$ & 15.836 & $\mathrm{O} 3$ & $x, y, z$ & 24.465 & 43.754 \\
\hline 01 & Ca1 & $\mathrm{x}, \mathrm{y}, \mathrm{z}$ & 22.777 & 03 & $\mathrm{x}, \mathrm{y}, \mathrm{z}$ & 24.465 & 112.742 \\
\hline $\mathrm{O} 2$ & $\mathrm{O} 2$ & $\mathrm{x}, \mathrm{y}, 0.5-\mathrm{z}$ & 0.3855 & P1 & $x, y, z$ & 15.401 & 90.000 \\
\hline $\mathrm{O} 2$ & P1 & $\mathrm{x}, \mathrm{y}, \mathrm{z}$ & 15.401 & $\mathrm{O} 3$ & $\mathrm{x}, \mathrm{y}, \mathrm{z}$ & 24.090 & 32.871 \\
\hline $\mathrm{O} 2$ & P1 & $\mathrm{x}, \mathrm{y}, 0.5-\mathrm{z}$ & 15.877 & Ca1 & $1-x, 1-y,-z$ & 23.223 & 115.029 \\
\hline $\mathrm{O} 2$ & Ca1 & $1-x, 1-y,-z$ & 23.223 & $\mathrm{O} 3$ & $\mathrm{x}, \mathrm{y}, \mathrm{z}$ & 24.090 & 73.250 \\
\hline $\mathrm{O} 2$ & $\mathrm{Ca} 2$ & $-x+y, 1-x, z$ & 23.586 & $\mathrm{Ca} 2$ & $-x+y, 1-x, 0.5-z$ & 23.899 & 9.283 \\
\hline $\mathrm{O} 2$ & $\mathrm{Ca} 2$ & $-x+y, 1-x, z$ & 23.586 & $\mathrm{O} 3$ & $\mathrm{x}, \mathrm{y}, \mathrm{z}$ & 24.090 & 137.796 \\
\hline $\mathrm{O} 2$ & $\mathrm{Ca} 2$ & $-x+y, 1-x, 0.5-z$ & 23.899 & 03 & $x, y, z$ & 24.090 & 143.219 \\
\hline $\mathrm{O} 2$ & $\mathrm{O} 2$ & $\mathrm{x}, \mathrm{y}, 0.5-\mathrm{z}$ & 0.3855 & P1 & $\mathrm{x}, \mathrm{y}, \mathrm{z}$ & 15.401 & 90.000 \\
\hline $\mathrm{O} 3$ & P1 & $\mathrm{x}, \mathrm{y}, \mathrm{z}$ & 13.939 & P1 & $\mathrm{x}, \mathrm{y}, 0.5-\mathrm{z}$ & 17.018 & 8.636 \\
\hline $\mathrm{O} 3$ & P1 & $\mathrm{x}, \mathrm{y}, 0.5-\mathrm{z}$ & 17.018 & 03 & $\mathrm{x}, \mathrm{y}, 0.5-\mathrm{z}$ & 24.728 & 32.884 \\
\hline $\mathrm{O} 3$ & $\mathrm{Ca} 2$ & $1+\mathrm{x}-\mathrm{y}, \mathrm{x},-\mathrm{z}$ & 21.584 & $\mathrm{O} 3$ & $x, y, 0.5-z$ & 24.728 & 158.840 \\
\hline $\mathrm{O} 3$ & $\mathrm{O} 2$ & $\mathrm{x}, \mathrm{y}, \mathrm{z}$ & 24.090 & $\mathrm{Ca} 2$ & $\mathrm{x},-1+\mathrm{y}, \mathrm{z}$ & 24.144 & 111.318 \\
\hline $\mathrm{O} 3$ & $\mathrm{Ca} 2$ & $\mathrm{x},-1+\mathrm{y}, \mathrm{z}$ & 24.144 & $\mathrm{O} 3$ & $\mathrm{x}, \mathrm{y}, 0.5-\mathrm{z}$ & 24.728 & 64.390 \\
\hline $\mathrm{O} 3$ & 01 & $\mathrm{x}, \mathrm{y}, \mathrm{z}$ & 24.465 & 03 & $\mathrm{x}, \mathrm{y}, 0.5-\mathrm{z}$ & 24.728 & 64.749 \\
\hline 04 & 04 & $-x+y,-x, 0.5-z$ & 0.6471 & $\mathrm{H} 4$ & $\mathrm{x}, \mathrm{y}, \mathrm{z}$ & 0.8949 & 180.000 \\
\hline 04 & $\mathrm{H} 4$ & $\mathrm{x}, \mathrm{y}, \mathrm{z}$ & 0.8949 & $\mathrm{H} 4$ & $-\mathrm{x}+\mathrm{y},-\mathrm{x}, 0.5-\mathrm{z}$ & 15.420 & 180.000 \\
\hline 04 & $\mathrm{H} 4$ & $-\mathrm{x}+\mathrm{y},-\mathrm{x}, 0.5-\mathrm{z}$ & 15.420 & $\mathrm{H} 4$ & $-\mathrm{x},-\mathrm{y},-\mathrm{z}$ & 19.000 & 180.000 \\
\hline 04 & $\mathrm{H} 4$ & $-\mathrm{x},-\mathrm{y},-\mathrm{z}$ & 19.000 & $\mathrm{Ca} 2$ & $\mathrm{x},-1+\mathrm{y}, \mathrm{z}$ & 23.594 & 93.178 \\
\hline 04 & $\mathrm{Ca} 2$ & $\mathrm{x},-1+\mathrm{y}, \mathrm{z}$ & 23.594 & $\mathrm{Ca} 2$ & $1-y, 1+x-y, z$ & 23.594 & 119.695 \\
\hline $\mathrm{O} 4$ & $\mathrm{Ca} 2$ & $\mathrm{x},-1+\mathrm{y}, 0.5-\mathrm{z}$ & 24.117 & $\mathrm{Ca} 2$ & $\begin{array}{l}1-y, 1+x-y \\
0.5-z\end{array}$ & 24.117 & 115.547 \\
\hline $\mathrm{H} 4$ & 04 & $\mathrm{x}, \mathrm{y}, \mathrm{z}$ & 0.8949 & $\mathrm{H} 4$ & $-\mathrm{x},-\mathrm{y},-\mathrm{z}$ & 10.051 & 180.000 \\
\hline $\mathrm{H} 4$ & $\mathrm{H} 4$ & $-\mathrm{x},-\mathrm{y},-\mathrm{z}$ & 10.051 & 04 & $-x+y,-x, 0.5-z$ & 15.420 & 180.000 \\
\hline $\mathrm{H} 4$ & 04 & $-\mathrm{x}+\mathrm{y},-\mathrm{x}, 0.5-\mathrm{z}$ & 15.420 & $\mathrm{O} 4$ & $-\mathrm{x},-\mathrm{y},-\mathrm{z}$ & 19.000 & 180.000 \\
\hline $\mathrm{H} 4$ & 04 & $-\mathrm{x},-\mathrm{y},-\mathrm{z}$ & 19.000 & $\mathrm{H} 4$ & $-x+y,-x, 0.5-z$ & 24.370 & 180.000 \\
\hline
\end{tabular}

calcium hydroxyapatite. To save the space, the repeated operations are not included, which the same value and the data will give detailed information of the sample.

The FullProf program was used to determine the crystal structure of the samples. Further data such as the contents of the unit cell based on the formula sum for $\mathrm{HAp}\left[\mathrm{Ca}_{10}\left(\mathrm{PO}_{4}\right)_{6}(\mathrm{OH})_{2}\right]$ was entered atom by atom.

All diffraction patterns displayed show similarities and point out the analogy between the structures of bone and Hap. However, the hexagonal symmetry works well, when dealing withdiffraction data, and the crystal structure of synthetic HAp is usually described in space group $\mathrm{P} 63 / \mathrm{m}$ with a hexagonal unit cell. Good structure refinements were obtained by varying the scale factor, background coefficients, unit-cell axes ( $a=b$ and $c$ ), and profile-function parameters. Atomic thermal factors, site occupancies, and atomic positions were kept fixed during the refinement, because the quality of the diffraction patterns was not sufficient to refine the crystal structure. The parameters that, we refined are independent of peak intensities and therefore are not affected by absorption conditions and (weak) preferred orientation. The broad $2 \theta$ peak around $30^{\circ}$ to $35^{\circ}$ detected at all the sample was consistent with the advancement of crystallization toward HA from the amorphous state, and became gradually higher.

The background was described using a 12-term shiftedChebishev function, and the diffraction profile was modeled by a pseudo-Voigt peak-shape function as implemented in the FullProf software package. Observing the diffraction patterns, it was noticed, that the diffraction peaks of rat bone and lumber vertebra $(8 \mathrm{w})$ are less broad than the diffraction peaks of rat bone (56 and $78 w$ ) and Hap. This feature clearly indicates that young rat bone samples are more poorly crystallized, dense meshed structure than the older ones (56 and $78 \mathrm{w}$ ), which suggests that the diffracting particles (crystallites) in the younger bone are smaller and older ones are much larger.

Diffraction peaks of Hap (Figs.6 to 8), especially the three strongest peaks of HAP at $2 \theta=25.88,31.88$ and 32.98 , which can be indexed as

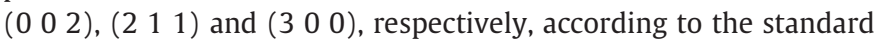
data (International Centre for Diffraction Data, Powder Diffraction File, 09-0432). The XRD spectra reveals that the structure of as-synthesized HAP belongs to the hexagonal $\mathrm{P} 63 / \mathrm{m}$ space group with lattice constant of $a=b=9.4238 \AA$ and $c=6.8842 \AA$. 


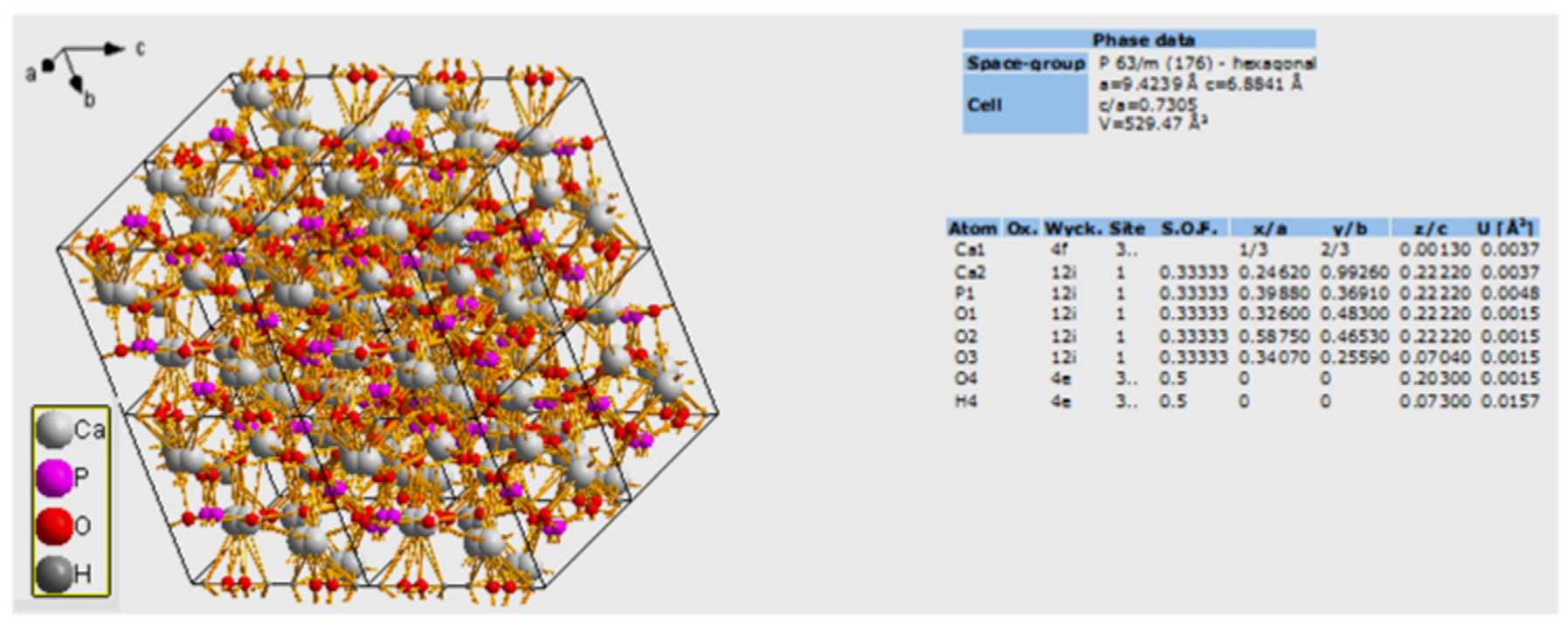

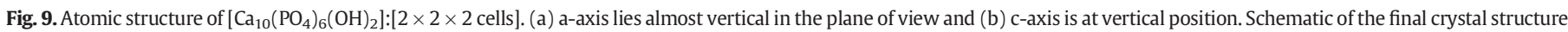
of the HAP sample along a-axis calculated by Rietveld refinement. The inset has phase data and atomic position values.

The final mineral crystalline phase was confirmed from the collection of XRD d-spacing's that correlated well with the Joint Committee on Powder Diffraction Standards (JCPDS) files for HAp. The variation of intensity with d-spacing for the hydroxyapatite sample is displayed in Fig.9. HAp exhibited numerous sharp diffraction peaks, indicating that its structure exhibited crystalline characteristics, and is in agreement with the reported crystal structure for this compound. The HAP diffraction pattern matched the HAp data obtained from the International Centre for Diffraction Data (ICDD) database. Phase identification was performed with reference to the library database supplied by the International Centre for Diffraction Data (ICDD) by directly comparing the X-ray diffraction spectra. All the XRD spectra obtained have characteristic peaks consistent with the International Centre for Diffraction Data (ICDD) files for calcium phosphates. The predominant phase, as expected, was confirmed with JCPDS file no. 9-432 for stoichiometric HAp. The hexagonal primitive cell of P63/m symmetry (\#176 in the International X-ray Tables) that contains $10 \mathrm{Ca}$ atoms, six phosphate (PO4) groups, and two hydroxyl $(\mathrm{OH})$ molecules.
Fig. 10 shows, atomic structure of $\left[\mathrm{Ca}_{10}\left(\mathrm{PO}_{4}\right)_{6}(\mathrm{OH})_{2}\right]:[2 \times 2 \times 2$ cells]. (a) a-axis lies almost vertical in the plane of view and (b) c-axis is at vertical position. Schematic of the final crystal structure of the HAP sample along a-axis calculated by Rietveld refinement. The inset has phase data and atomic position values.

The critical atoms in structure picture around $\mathrm{Ca}=304, P=128$, $==640$ and for $\mathrm{H}=72$. The histograms are displaced in Fig.11(a) to (e) to have an insight of the diffraction pattern. Two groups of XRD reflection peaks can be used to monitor the HAp formation; one at $2 \theta=26^{\circ}$ and the other group is ranging from $2 \theta=30$ to $34^{\circ}$. For quantitative purposes, it is recommended to consider the data from $2 \theta=$ $26^{0}$,which corresponds to $\left(\begin{array}{lll}0 & 0\end{array}\right)$ reflection peak, and is well resolved, with no interferences.

For a given animal age and degree of mineralization, crystallinity increases with animal age, indicating that changes in bone mineral occur even after mineralization is complete or nearly complete. A high crystallinity in the low-to-medium density, presumably younger bone $(8 \mathrm{w})$; a lower crystallinity in the middle density ranges (56w); and a higher crystallinity in the highest density $(78 \mathrm{w})$, oldest fraction.

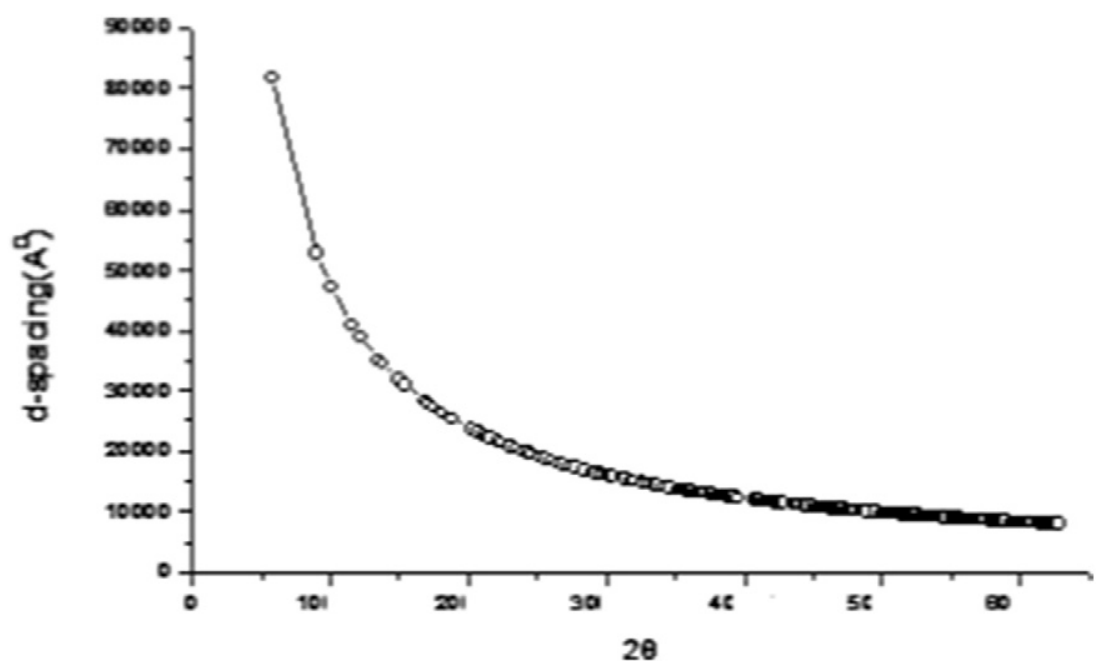

Fig. 10. Variation of d-spacing with 2theta for the hydroxyapatite sample at $15 \mathrm{keV}$. 


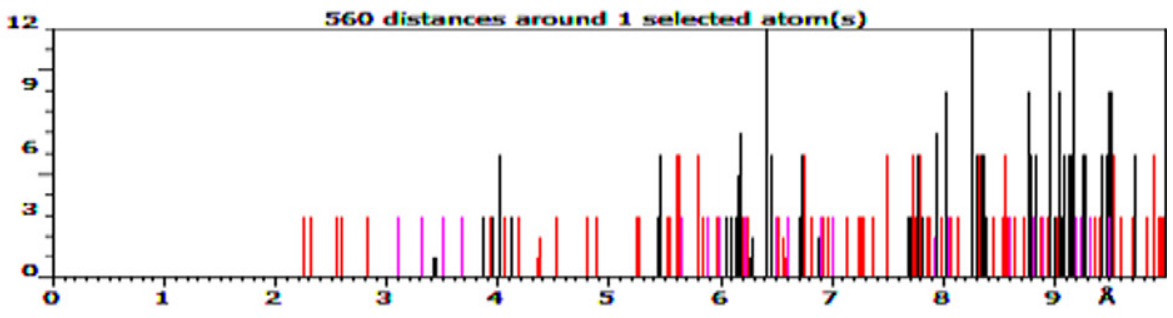

(a) Histogram of distances of selected atoms around $\mathrm{Ca} 1$

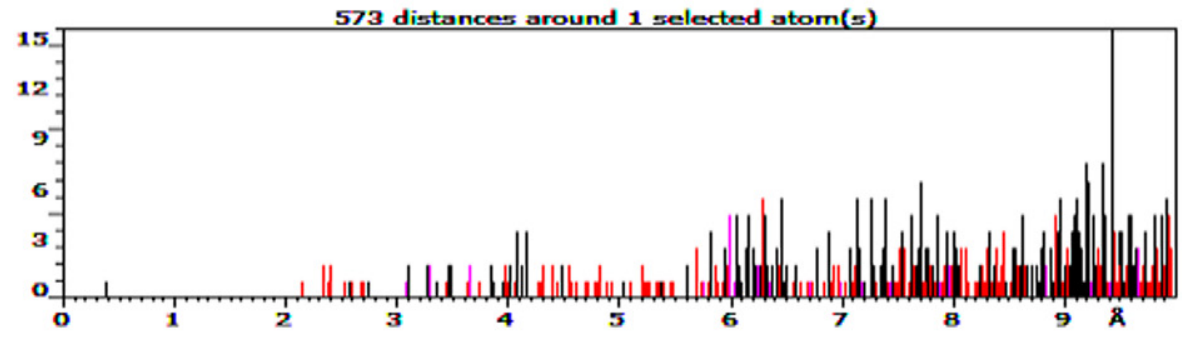

(b) Histogram of distances of selected atoms around $\mathrm{Ca} 2$

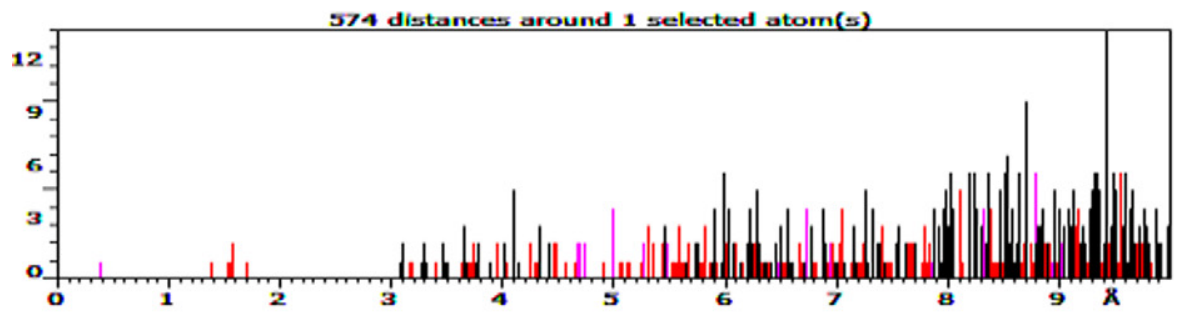

(c) Histogram of distances of selected atoms around P1

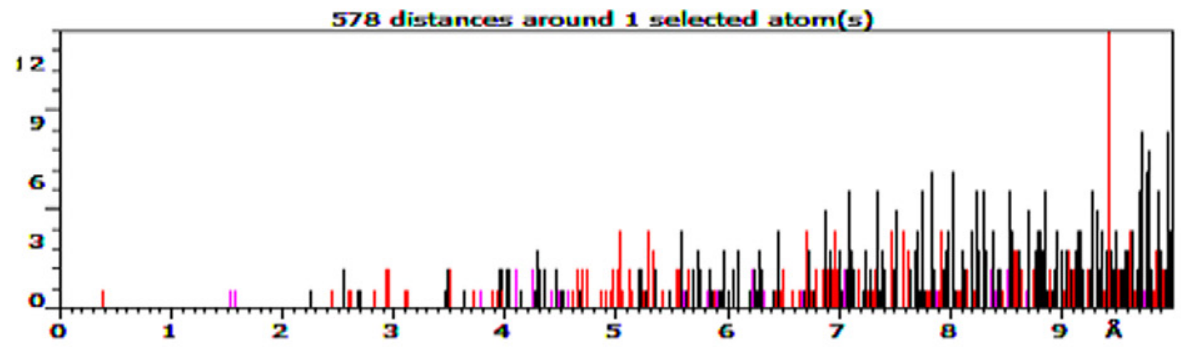

(d) Histogram of distances of selected atoms around $\mathrm{O} 1$

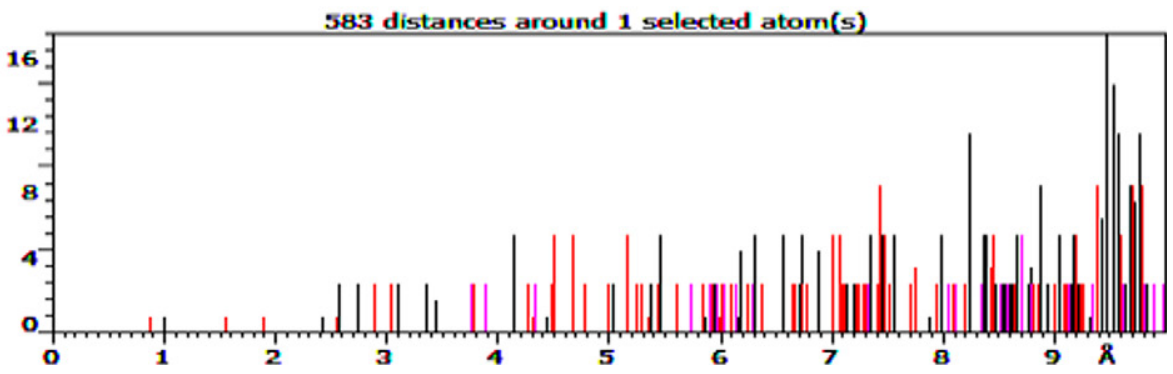

(e) Histogram of distances of selected atoms around H4

Fig. 11. (a) to (e). Histogram of distances of selected atoms.

The HAp powder samples are non-conducting, by nature. In order to prevent charging from occurring during examination, sample preparation for each HAp sample was undertaken. The first stage involved suspending HAp with a glue on an aluminum stub. The samples were allowed a sufficient period to dry (10 min). After which, any excess powder was eliminated with an air hose at low pressure prior to the carbon coating process. The Edwards Scancoat six sputter coaterwas used to apply a layer of carbon onto the HAp samples, in order to increase the electrical conductivity of the specimen sample during SEM operation and hence provide a clear analysis of the individual HAp powder particles and/or particle aggregates morphological properties. The samples were investigated for their microstructural and morphological 
features by using a scanning electron microscopy operated at a typical accelerating voltage of $20 \mathrm{kV}$.

The image is an artificial map of the surface, that is, there are no direct ray paths linking the specimen to the projected image, as is the case in optical and transmission microscopes. Instead, the area under observation is irradiated with a finely focused electron beam of between 10 and $25 \mathrm{kV}$, which may be static or swept in a raster across the surface of the material in synchronism with a spot on a cathode ray tube (CRT). A detector monitors the scattered electron (SE) (including back scattered electron (BSE)) signals and the brightness of the spot on the CRT is controlled by an amplified version of the detected signal. The scan of the CRT is fixed and the effect of reducing the area scanned on the specimen is to increase the magnification of the map. The intensities of the SE and BSE generated are dependent on the angle of incidence between the beam and the specimen. The angle of incidence will vary because of the roughness of the material, leading to the development of contrast, which relates to the physical nature of the specimen. The surfaces facing the light source appear bright while those facing away range from grey to black. Hence, only the surfaces which face the detector provide a strong enough signals to obtain a useful image, while black are indicative of a tilted surface. The high-magnification SEM images shows the samples are porous structure, which is very useful for biomedical applications.

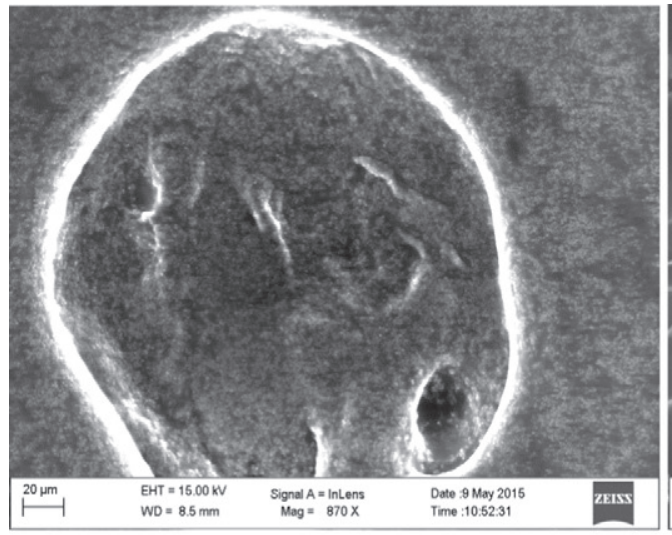

(a) $8 \mathrm{w} 1$

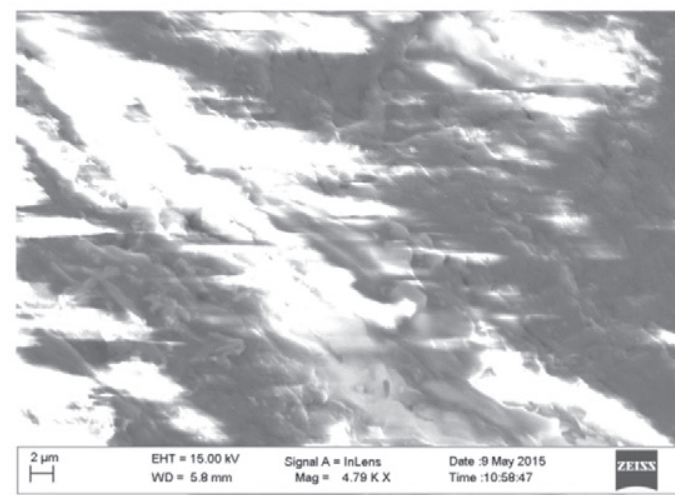

(c) $56 \mathrm{w} 1$

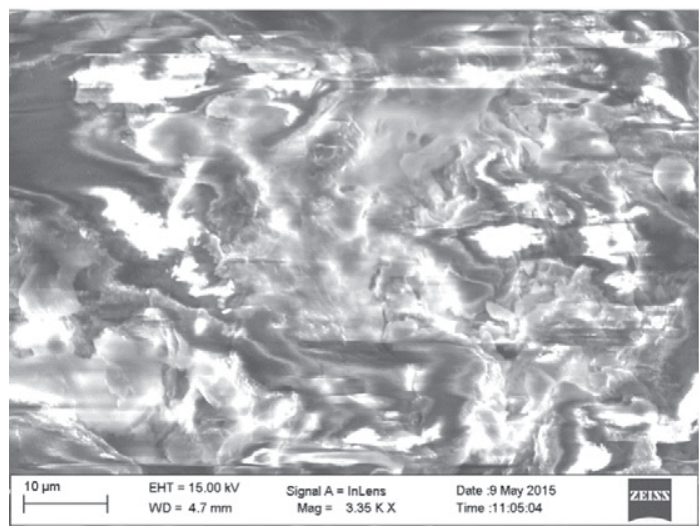

(e) $78 \mathrm{w} 1$

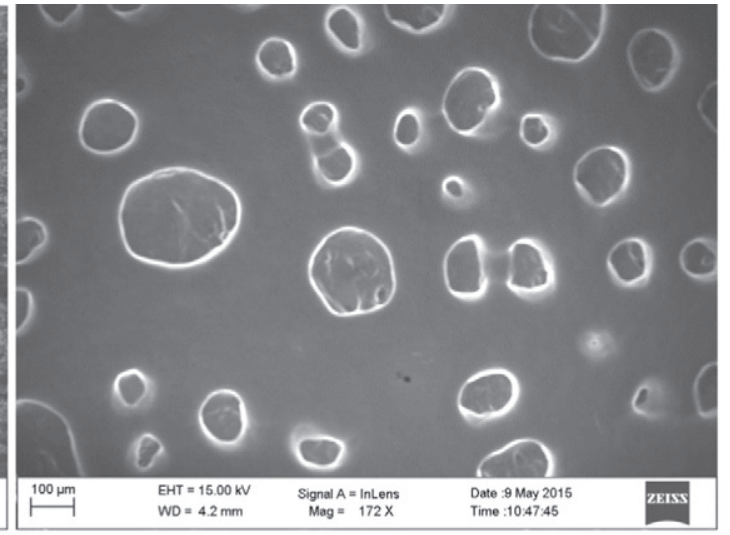

(b) $8 \mathrm{w} 2$

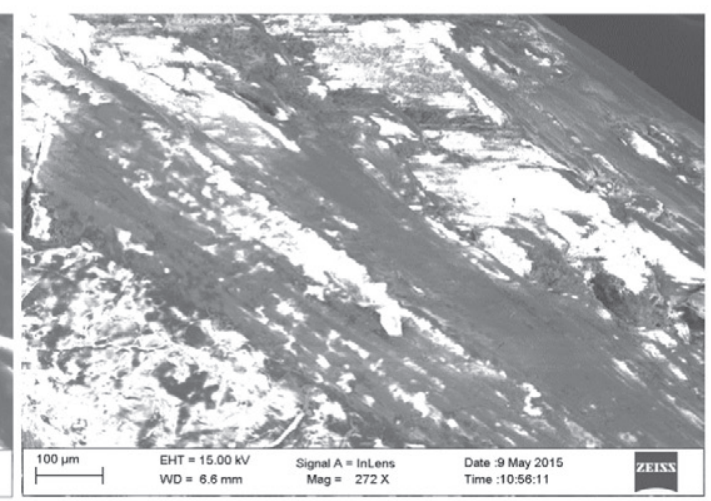

(d) $56 \mathrm{w} 2$

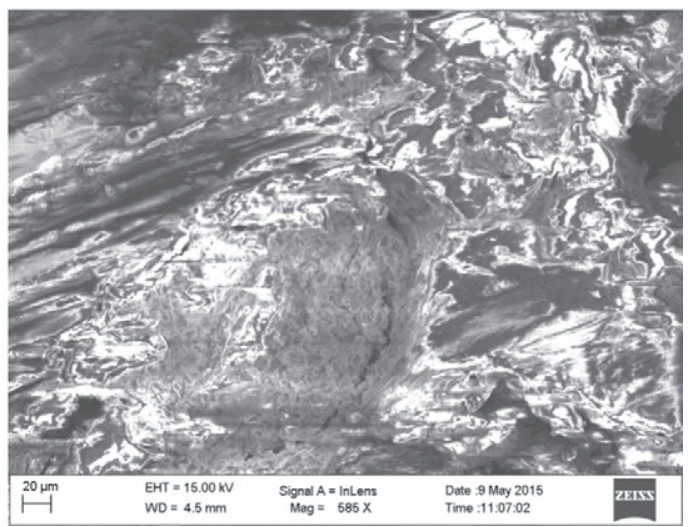

(f) $78 \mathrm{w} 2$

Fig. 12. (a) to (n) shows the SEM images of all the samples used. 


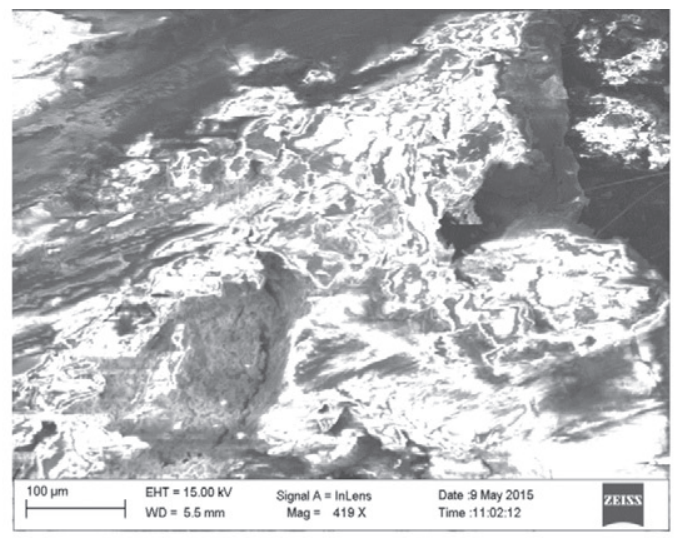

(f) $78 \mathrm{w} 3$

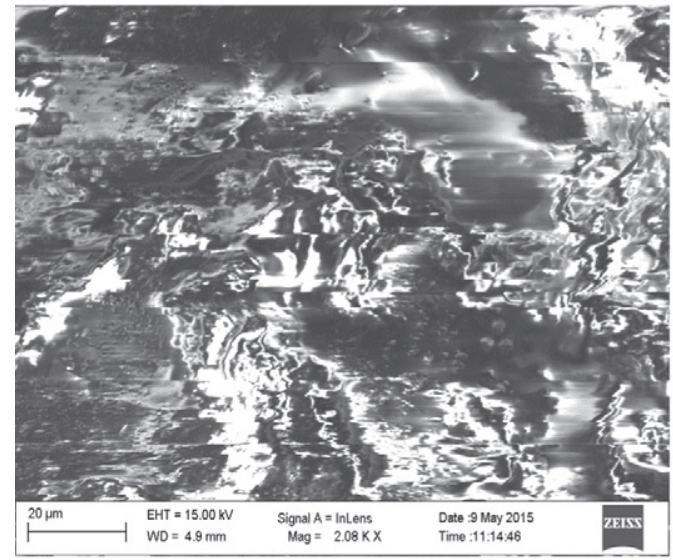

(g) LV1

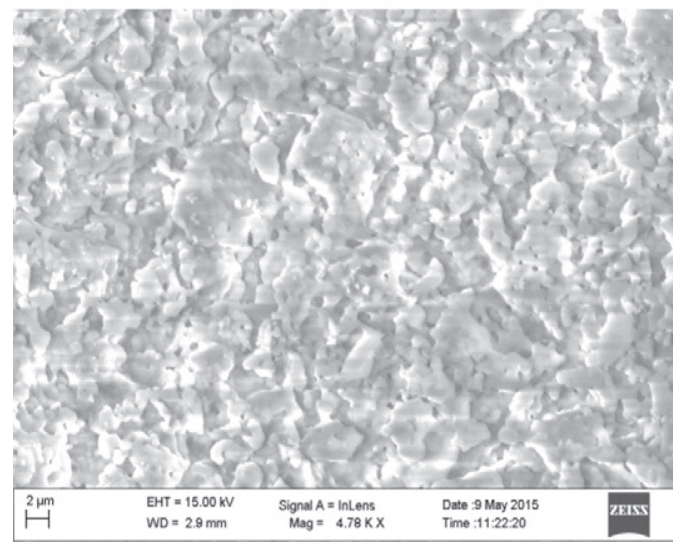

(i) Bone cream 1

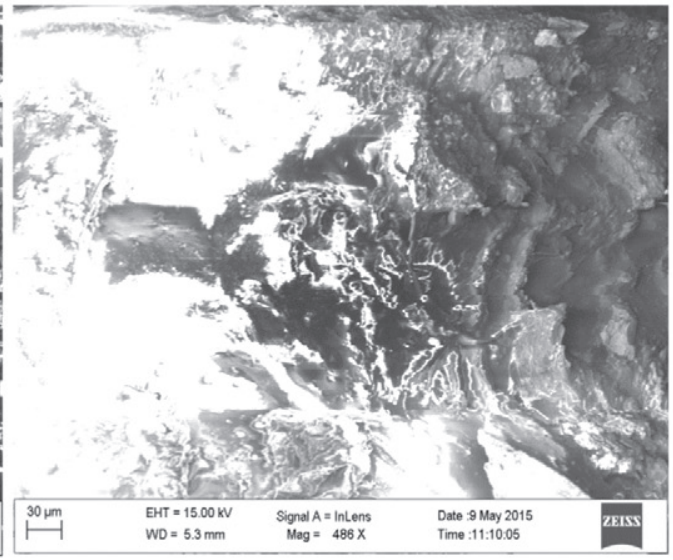

(h) LV2

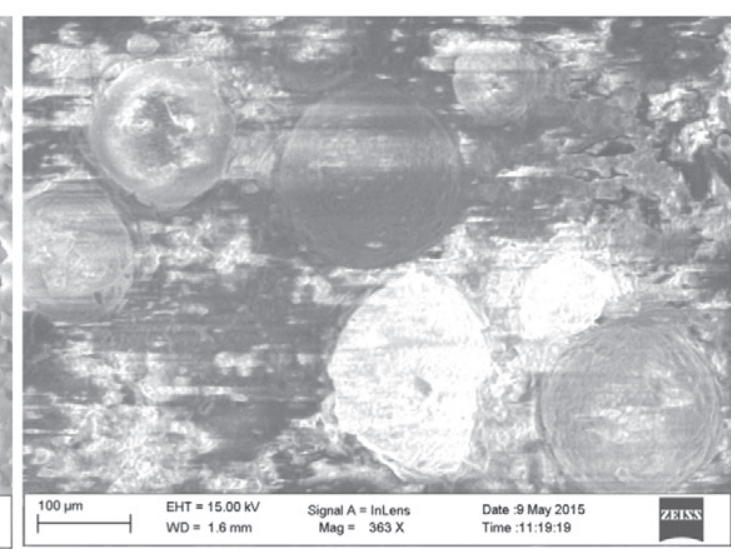

(j) Bone cream 2

Fig. 12 (continued).

The surface morphology and crystalline properties of rat bone of different age groups, lumber vertebra, bone fill with different composition and bone cream, were further characterized by SEM; the resulting micrographs are displayed in Fig.12(a) to (n). For the 8 weeks rat, we used two different resolutions of 20 and $100 \mu \mathrm{m}$. At $20 \mu \mathrm{m}$, the structure of the sample is poor in crystalline nature, with increased resolution, we noticed the visible porosity,with less dense mesh structure, as distinguished, with 56 and 78 weeks rat bone and also with rat lumber vertebra with enhanced morphology. With extended resolution, the nature of the sample, looks like a long-shaped crystalline in nature. However, for Hap, at various composition(60\% and $70 \%$ ) and also in bone cream (35-48\%), contained crystals with an agglomerated structure.

\section{Conclusion}

Our research is focused on studying and understanding the structural properties of these samples, with an aim to explore the importance of these materials at the nano-level scale. 


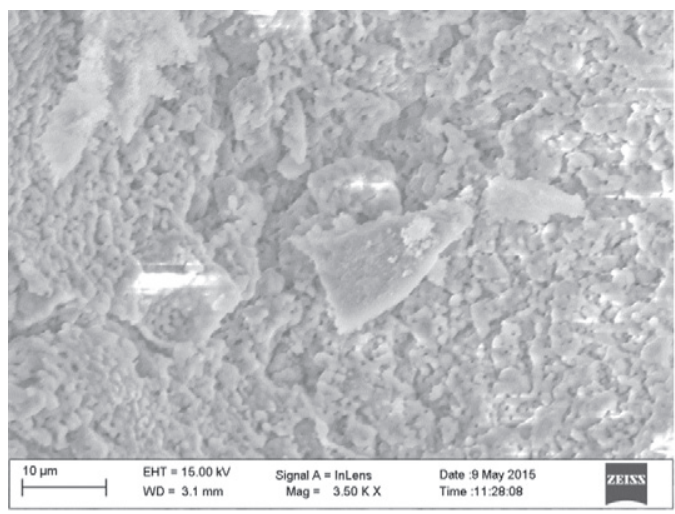

(k) Bone fill $60 \% 1$

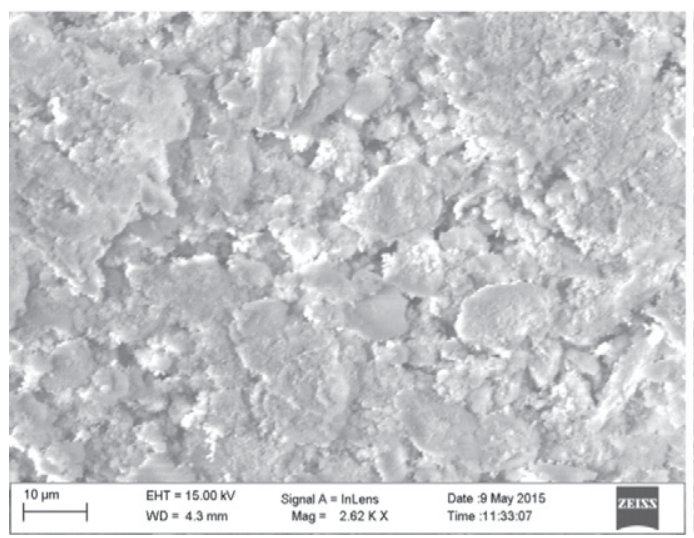

(m) Bone fill $70 \% 1$

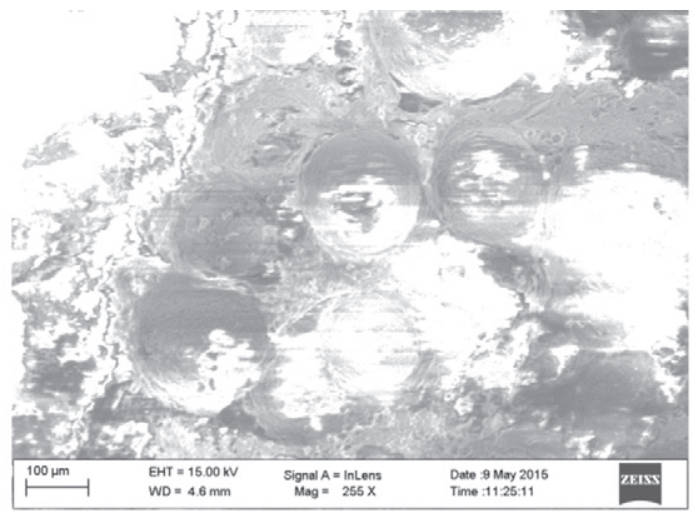

(1) Bone fill $60 \% 2$

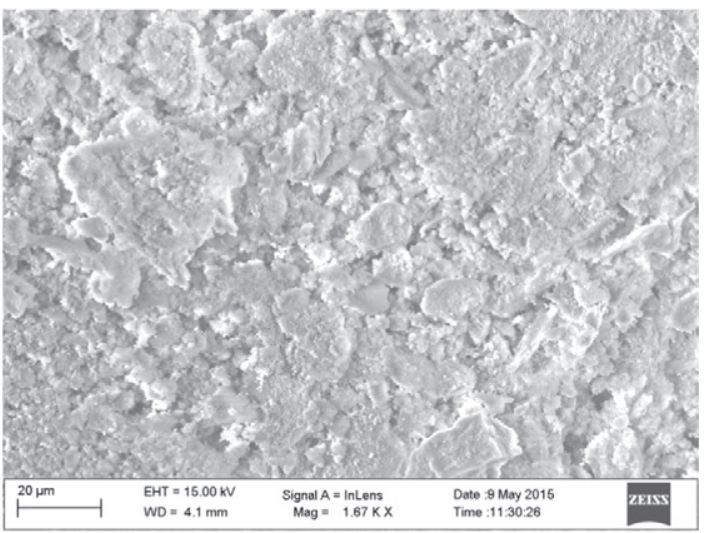

(n) Bone fill $70 \% 2$

Fig. 12 (continued).

\section{Acknowledgments}

One of the author's (DVR) undertook part of this work with a support from, Science Based Applications to Engineering, University of Rome "La Sapienza", Via Scarpa 10, 00161, Roma, Italy, Istituto di Matematica e Fisica, University of Sassari, Italy, and Department of Bio-Systems Engineering, Yamagata University, Yonezawa, Japan GE1,US1. Travel support (DVR) received from the DST window, Saha Institute of Nuclear Physics, India.

\section{References}

[1] J.J. Wu, L. Zhao, E.L. Chronister, S.H. Tolbert, Elasticity through nanoscale distortions in periodic surfactant-templated porous silica under high pressure, J. Phys. Chem. B 106 (2002) 5613.

[2] S.V. Dorozhkin, M. Epple, Biological and medical significance of calcium phosphates, Angew. Chem. Int. Ed. 41 (2002) 3130.

[3] T.C.A. McGann, R.D. Kearney, W. Buchheim, A.S. Posner, F. Betts, N.C. Blumenthal, Amorphous calcium phosphate in casein micelles of bovine milk, Calcif. Tissue Int. 35 (1983) 821.
[4] F. Gaucheron, Calcium phosphates in dairy products, in: R.B. Heimann (Ed.), Calcium Phosphate: Structure, Synthesis, Properties and Applications, Nova Science Publishers, Inc., New York 2012, p. 381.

[5] F. Brunet, D.R. Allan, S.A.T. Redfern, R.J. Angel, R. Miletich, H.J. Reichmann, J. Sergent, M. Hanfland, Compressibility and thermal expansivity of synthetic apatites, Ca5(PO4)3X with X = OH, F and Cl, Eur. J. Mineral. 11 (1999) 1023.

[6] E.D. Eanes, Amorphous calcium phosphate: thermodynamic and rkinetic considerations, in: Z. Amjad (Ed.), Calcium Phosphates in Biological and Industrial Systems, Kluwer Academic Publishers, Massachusetts 1998, p. 21.

[7] C. Combes, C. Rey, Amorphous calcium phosphates: synthesis, properties and uses in biomaterials, Acta Biomater. 6 (2010) 3362.

[8] M. Jarcho, C.H. Bolen, M.B. Thomas, J. Bobick, J.F. Kay, R.H. Doremus, Hydroxylapatite synthesis and characterization in dense polycrystalline form, J. Mater. Sci. 11 (1976) 2027.

[9] J.C. Elliot, Structure and Chemistry of Apatites and Other Calcium Orthophosphates, Elsevier, Amsterdam, The Netherlands, 1994.

[10] A.S. Posner, F. Betts, Synthetic amorphous calcium phosphate and its relation to bone mineral structure, Acc. Chem. Res. 8 (1975) 273.

[11] M.I. Kay, R.A. Young, A.S. Posner, Crystal structure of hydroxyapatite, Nature 204 (1964) 1050.

[12] J. Rodriguez-Carvajal, FullProf Computer Programme, 2005. 